\title{
What We Don't Know Doesn't Hurt Us: Rational Inattention and the Permanent Income Hypothesis in General Equilibrium
}

\author{
Yulei Luo* \\ Jun $\mathrm{Nie}^{+}$ \\ University of Hong Kong \\ Federal Reserve Bank of Kansas City \\ Gaowang Wang $\ddagger$ \\ Eric R. Young $\S$ \\ Shandong University \\ University of Virginia
}

October 18, 2014

\begin{abstract}
This paper derives the general equilibrium effects of rational inattention (or RI; Sims 2003, 2010) in a model of incomplete income insurance (Huggett 1993, Wang 2003). We show that, under the assumption of CARA utility with Gaussian shocks, the permanent income hypothesis $(\mathrm{PIH})$ arises in steady state equilibrium due to a balancing of precautionary savings and impatience. We then explore how RI affects the equilibrium joint dynamics of consumption, income and wealth, and find that elastic attention can make the model fit the data better. We finally show that the welfare costs of incomplete information are even smaller due to general equilibrium adjustments in interest rates.
\end{abstract}

Keywords: Rational Inattention; Permanent Income Hypothesis; General Equilibrium; Consumption and Income Volatility.

JEL Classification Numbers: C61; E21; D83.

\footnotetext{
*Faculty of Business and Economics, The University of Hong Kong, Hong Kong. E-mail: yluo@econ.hku.hk.

${ }^{\dagger}$ Research Department, Federal Reserve Bank of Kansas City. E-mail: jun.nie@kc.frb.org.

‡Center for Economic Research, Shandong University, Jinan, China. E-mail: wanggaowang@gmail.com.

§Department of Economics, University of Virginia, Charlottesville, VA 22904. E-mail: ey2d@virginia.edu.
} 


\section{Introduction}

In intertemporal consumption-savings problems, households save today for three reasons: (i) they anticipate future declines in income, (ii) they face uninsurable risk that generates precautionary savings, and (iii) they are relatively patient compared to the interest rate. When only motive (i) is operative then one obtains the "permanent income hypothesis (PIH)" of Friedman (1957), where consumption is solely determined by permanent income and follows a random walk. (See also Hall 1978.) The PIH has some implications that are strongly inconsistent with the data. Two implications in particular are discussed in Campbell and Deaton (1989), the excess sensitivity and excess smoothness puzzles. Excess sensitivity occurs if consumption responds to predictable changes in income; under the PIH those changes are part of permanent income and therefore have already had their effect on consumption. Excess smoothness occurs if consumption responds less than one for one to permanent changes in income (or equivalently less than one for one to changes in permanent income). The two puzzles are actually manifestations of the same underlying economic forces, as shown in Campbell and Deaton (1989), and their absence is profoundly rejected. Uninsurable income risk seems to be pervasive in microeconomic data, and general equilibrium models with uninsurable risk tend to predict impatience of households (that is, they face "low interest rates"), so that the basic PIH is violated.

Wang (2003), using a simple model with CARA utility and risk free assets in zero net supply, shows that the PIH reemerges in general equilibrium - when decision rules are linear, the equilibrium interest rate exactly balances the forces of precautionary saving and dissaving due to impatience, even in the presence of uninsurable risk. Due to the linearity of consumption as a function of individual permanent income, Wang (2003) is able to analytically characterize the forces that operate in general equilibrium and show they cancel out, under some mild assumptions about the labor income process.

Luo (2008) and Luo and Young (2010) introduce rational inattention into the basic partial equilibrium PIH environment; RI implies that agents process signals slowly and therefore appear to respond sluggishly to innovations in permanent income. This sluggish response appears to deliver changes in consumption in response to anticipated income changes, because econometricians actually observe more than the agents do, and as a result also delivers smaller responses to permanent income changes. ${ }^{1}$

\footnotetext{
${ }^{1}$ The literature that rejects the PIH empirically is vast, suggesting that the reemergence is not something desireable. However, the tests of the $\mathrm{PIH}$, while robust to the possibility that agents have more information than the econometrician
} 
Our goal in this paper is to explore the general equilibrium implications of rational inattention in a model with precautionary savings and ask the same question from Wang (2003) - namely, does the $\mathrm{PIH}$ reemerge in general equilibrium - in the presence of rational inattention. We study economies with constant absolute risk aversion (CARA) preferences, as they simultaneously generate precautionary savings and linear consumption rules, and characterize the forces that act on the general equilibrium interest rate. ${ }^{2}$ We find that the PIH does describe equilibrium consumption behavior in general equilibrium, with the appropriate substitution of actual permanent income by perceived permanent income. Thus, the delicate canceling of precautionary and impatience forces found by Wang (2003) carries over unmodified to models with incomplete information about the state. ${ }^{3}$ We also compare rational inattention with habit formation; although both models lead to slow adjustment in consumption, they have opposite effects on the equilibrium interest rate and the relative volatility of consumption to income growth.

One key result in this paper is that there exists general equilibrium interest rates clearing the asset market and they are significantly affected by the degree of RI. After obtaining the explicit expression for consumption dynamics, we examine how RI affects the stochastic properties of the joint dynamics of consumption growth to income growth in both the fixed capacity and elastic capacity cases. Specifically, we find that the effect of RI on consumption dynamics is attenuated by general equilibrium adjustment in the interest rate - as processing capacity declines the interest rate also declines, leading to lower consumption volatility. The implication is that the costs of incomplete information have likely been overestimated in the literature, despite being very tiny to start. ${ }^{4}$

This paper is organized as follows. Section 2 constructs a precautionary saving model with a continuum of inattentive consumers who have the CARA utility and face uninsurable labor income. Section 3 solves optimal consumption-saving rules under rational inattention and establishes the general equilibrium of this economy. Section 4 examines how RI affects the interest rate and the joint dynamics of consumption, income, and wealth quantitatively. Section 5 considers an extension

(see Campbell and Deaton 1989), they are not robust to the RI implication that the econometrician may actually have more information than the agents (at least at the time of decisions).

${ }^{2}$ Note that while the constant-relative-risk-aversion (CRRA) utility function is more commonly used in economics, this utility will greatly complicate our annalysis because the intetemporal consumption model with CRRA utility and stochastic labor income has no explicit solution and leads to non-linear consumption rules.

${ }^{3}$ Luo and Young (2014) document a observational equivalence between rational inattention and signal extraction in linear-quadratic-Gaussian models.

${ }^{4}$ For the welfare losses due to imperfect information about current income or permanent income calculated in the partial equilibrium linear-quadratic (LQ) permanent income models, see Pischke (1995), Luo and Young (2010), and Luo, Nie, and Young (2014). Maćkowiak and Wiederholt (2013) also find tiny welfare losses due to RI in a general equilibrium business cycle model. 
to the recursive utility setting. Section 6 concludes.

\section{A Caballero-Huggett-Wang Economy with Rational Inattention}

\subsection{A Full-information Rational Expectations Model with Precautionary Savings}

Following Caballero (1990) and Wang (2003), we formulate a full-information rational expectations (FI-RE) model with precautionary savings as follows:

$$
V\left(a_{0}, y_{0}\right)=\max _{\left\{c_{t}, a_{t}\right\}_{t=0}^{\infty}}\left\{E_{0}\left[\sum_{t=0}^{\infty}\left(\frac{1}{1+\rho}\right)^{t} u\left(c_{t}\right)\right]\right\},
$$

subject to the flow budget constraint

$$
a_{t+1}=(1+r) a_{t}+y_{t}-c_{t}
$$

where $u\left(c_{t}\right)=-\exp (-\alpha c) / \alpha$ is a constant-absolute-risk-aversion utility with $\alpha>0, \rho>0$ is the agent's subjective discount rate, $r$ is a constant rate of interest, and labor income, $y_{t}$, follows a stationary $\mathrm{AR}(1)$ process with Gaussian innovations

$$
y_{t}=\phi_{0}+\phi_{1} y_{t-1}+w_{t}, t \geq 1,\left|\phi_{1}\right|<1
$$

where $w_{t} \sim N\left(0, \sigma^{2}\right), \phi_{0}=\left(1-\phi_{1}\right) \bar{y}, \bar{y}$ is the mean of $y_{t}$, and the initial levels of labor income $y_{0}$ and asset $a_{0}$ are given. ${ }^{5}$ Solving (1) subject to (2) and (3) yields the following optimal consumption plan:

$$
c_{t}=r\left\{a_{t}+h_{t}+\frac{1}{\alpha r^{2}}\left[\ln \left(\frac{1+\rho}{1+r}\right)-\ln E_{t}\left[\exp \left(-r \alpha \phi w_{t+1}\right)\right]\right]\right\} .
$$

In this expression,

$$
h_{t} \equiv \frac{1}{1+r} E_{t}\left[\sum_{j=0}^{\infty}\left(\frac{1}{1+r}\right)^{j} y_{t+j}\right],
$$

is human wealth (defined as the discounted expected present value of current and future labor income); evaluating the sum yields

$$
h_{t}=\phi\left(y_{t}+\frac{\phi_{0}}{r}\right)
$$

\footnotetext{
${ }^{5}$ Assuming that the individual income shock includes two components, one permanent and the other transitory, does not change the main results in this paper. Here we follow Wang (2003) and adopt specification (3), in order to simplify the algebra. A detailed derivation of the model with the two-income shock specification is available from the corresponding author by request. For the empirical studies on the income specification, see Attanasio and Pavoni (2011).
} 
where $\phi=1 /\left(1+r-\phi_{1}\right) \cdot{ }^{6}$ This consumption function is the same as that obtained in Wang (2003). In the last two terms in (4), $\ln \left(\frac{1+\rho}{1+r}\right) / r \alpha$ measures the relative importance of impatience and the interest rate in determining current consumption, and $\ln \left(E_{t}\left[\exp \left(-r \alpha \phi w_{t+1}\right)\right]\right) / r \alpha$ measures the amount of precautionary savings determined by the interaction of risk aversion and income uncertainty.

In order to facilitate the introduction of rational inattention we follow Luo (2008) and Luo and Young (2010) and reduce the multivariate model to a univariate model with iid innovations to permanent income. Letting permanent income, $s_{t}=a_{t}+h_{t}$, be defined as a new state variable, we can reformulate the PIH model as

$$
v\left(s_{t}\right)=\max _{c_{t}}\left\{u\left(c_{t}\right)+\frac{1}{1+\rho} E_{t}\left[v\left(s_{t+1}\right)\right]\right\}
$$

subject to

$$
s_{t+1}=(1+r) s_{t}-c_{t}+\zeta_{t+1}
$$

where the time $(t+1)$ innovation to permanent income can be written as

$$
\zeta_{t+1} \equiv \frac{1}{1+r} \sum_{j=t+1}^{\infty}\left(\frac{1}{1+r}\right)^{j-(t+1)}\left(E_{t+1}-E_{t}\right)\left[y_{j}\right]
$$

which can be reduced to $\zeta_{t+1}=\phi w_{t+1}$ when we use the income specification, (3), where $v\left(s_{t}\right)$ is the consumer's value function under FI-RE. ${ }^{7}$

\subsection{Incorporating Rational Inattention}

In this section, we follow Sims (2003) and incorporate rational inattention (RI) due to finite informationprocessing capacity into the above permanent income model with the CARA-Gaussian specification. Under RI, consumers have only finite Shannon channel capacity available to observe the state of the world. Specifically, we use the concept of entropy from information theory to characterize the uncertainty about a random variable; the reduction in entropy is thus a natural measure of information flow. ${ }^{8}$ With finite capacity $\kappa \in(0, \infty)$, a random variable $\left\{s_{t}\right\}$ following a continuous dis-

\footnotetext{
${ }^{6}$ See Appendix 7.1 for the derivation.

${ }^{7}$ See Appendix 7.1 for the derivation.

${ }^{8}$ Formally, entropy is defined as the expectation of the negative of the (natural) log of the density function, $-E[\ln (f(s))]$. For example, the entropy of a discrete distribution with equal weight on two points is simply $E\left[\ln _{2}(f(s))\right]=-0.5 \ln (0.5)-0.5 \ln (0.5)=0.69$, and the unit of information contained in this distribution is 0.69 "nats". (For alternative bases for the logarithm, the unit of information differs; with log base 2 the unit of information is the 'bit' and with base 10 it is a 'dit' or a 'hartley.') In this case, an agent can remove all uncertainty about $s$ if the capacity devoted
} 
tribution cannot be observed without error and thus the information set at time $t+1$, denoted $\mathcal{I}_{t+1}$, is generated by the entire history of noisy signals $\left\{s_{j}^{*}\right\}_{j=0}^{t+1}$. Following the literature, we assume the noisy signal takes the additive form

$$
s_{t+1}^{*}=s_{t+1}+\xi_{t+1}
$$

where $\xi_{t+1}$ is the endogenous noise caused by finite capacity. ${ }^{9}$ We further assume that $\xi_{t+1}$ is an iid idiosyncratic shock and is independent of the fundamental shocks hitting the economy. The reason that the RI-induced noise is idiosyncratic is that the endogenous noise arises from the consumer's own internal information-processing constraint. Agents with finite capacity will choose a new signal $s_{t+1}^{*} \in \mathcal{I}_{t+1}=\left\{s_{1}^{*}, s_{2}^{*}, \cdots, s_{t+1}^{*}\right\}$ that reduces the uncertainty about the variable $s_{t+1}$ as much as possible. Formally, this idea can be described by the information constraint

$$
\mathcal{H}\left(s_{t+1} \mid \mathcal{I}_{t}\right)-\mathcal{H}\left(s_{t+1} \mid \mathcal{I}_{t+1}\right) \leq \kappa,
$$

where $\mathcal{K}$ is the investor's information channel capacity, $\mathcal{H}\left(s_{t+1} \mid \mathcal{I}_{t}\right)$ denotes the entropy of the state prior to observing the new signal at $t+1$, and $\mathcal{H}\left(s_{t+1} \mid \mathcal{I}_{t+1}\right)$ is the entropy after observing the new signal. $\kappa$ imposes an upper bound on the amount of information flow - that is, the change in the entropy - that can be transmitted in any given period. Finally, following the literature, we suppose that the prior distribution of $s_{t+1}$ is Gaussian.

Although we adopt the CARA-Gaussian setting in our model, we will assume the loss function due to imperfect-state-observation is still quadratic. Using a quadratic loss function, Sims (2003) shows that the true state under RI also follows a normal distribution $s_{t} \mid \mathcal{I}_{t} \sim N\left(E\left[s_{t} \mid \mathcal{I}_{t}\right], \Sigma_{t}\right)$, where $\Sigma_{t}=E_{t}\left[\left(s_{t}-\widehat{s}_{t}\right)^{2}\right] \cdot{ }^{10}$ In addition, given that the noisy signal takes the additive form $s_{t+1}^{*}=s_{t+1}+\xi_{t+1}$, the noise $\xi_{t+1}$ will also be Gaussian. Here we assume ex post Gaussian distributions and Gaussian noise but adopt CARA preferences. See Peng (2004), Mondria (2010), and to monitoring $s$ is $\kappa=0.69$ nats.

${ }^{9}$ For other types of imperfect information about state variables, see Pischke (1995) and Wang (2004). Pischke (1995) assumes that consumers ignore the aggregate income component, and Wang (2004) assume that consumers cannot distinguish two individual components in the income process.

${ }^{10}$ Shafieepoorfard and Raginsky (2013) formally derive the rational inattention solution using rate-distortion theory; while their solution is not identical to the certainty-equivalent one used here, it is quantitatively very similar. A comparison of the two solutions for the standard LQ-Gaussian PIH problem is available upon request. 
Van Nieuwerburgh and Veldkamp (2010) for this specification. ${ }^{11}$ In this case, (8) reduces to

$$
\ln \left(\left|\Psi_{t}\right|\right)-\ln \left(\left|\Sigma_{t+1}\right|\right) \leq 2 \kappa,
$$

where $\Sigma_{t+1}=\operatorname{var}_{t+1}\left(s_{t+1}\right)$ and $\Psi_{t}=\operatorname{var}_{t}\left(s_{t+1}\right)=(1+r)^{2} \Sigma_{t}+\operatorname{var}_{t}\left(\zeta_{t+1}\right)$ are the posterior and prior variance of the state variable, $s_{t+1}$, respectively. In our univariate model, (9) fully determines the value of the steady state conditional variance $\Sigma$ :

$$
\Sigma=\frac{\operatorname{var}_{t}\left(\zeta_{t+1}\right)}{\exp (2 \kappa)-(1+r)^{2}}
$$

which means that $\Sigma$ is entirely determined by the variance of the exogenous shock $\left(\operatorname{var}_{t}\left(\zeta_{t+1}\right)\right)$ and finite capacity $(\kappa) .{ }^{12}$ Following the steps outlined in Luo and Young (2014), we can compute the Kalman gain in the steady state $\theta$ as

$$
\theta=1-1 / \exp (2 \kappa)
$$

$\theta$ measures the fraction of uncertainty removed by a new signal in each period. ${ }^{13}$

The evolution of the estimated state $\widehat{s}_{t}$ is governed by the Kalman filtering equation

$$
\widehat{s}_{t+1}=(1-\theta)\left((1+r) \widehat{s}_{t}-c_{t}\right)+\theta s_{t+1}^{*} .
$$

Combining (6) with (12) yields

$$
\widehat{s}_{t+1}=(1+r) \widehat{s}_{t}-c_{t}+\widehat{\zeta}_{t+1}
$$

where

$$
\widehat{\zeta}_{t+1}=\theta(1+r)\left(s_{t}-\widehat{s}_{t}\right)+\theta\left(\zeta_{t+1}+\zeta_{t+1}\right)
$$

is the innovation to $\widehat{s}_{t+1}$ and is independent of all the other terms on the RHS of (13). $\widehat{\zeta}_{t+1}$ is an

\footnotetext{
${ }^{11}$ Because both the optimality of ex post Gaussianity and the standard Kalman filter are based on the linear-quadraticGaussian specification, the applications of these results in the RI models with CARA preferences are only approximately valid.

${ }^{12}$ Note that here we need to impose the restriction $\exp (2 \kappa)-(1+r)^{2}>0$. If this condition fails, the state is not stabilizable and the unconditional variance diverges.

${ }^{13}$ In Section 3.3 we model RI as confronting the agent with a fixed marginal cost of acquiring channel capacity. Luo and Young (2014) show the two are observationally equivalent with respect to consumption-income dynamics, but the effects on equilibrium interest rates will be different.
} 
$\operatorname{MA}(\infty)$ process with $E_{t}\left[\widehat{\zeta}_{t+1}\right]=0$ and

$$
\operatorname{var}\left(\widehat{\zeta}_{t+1}\right)=\Gamma(\theta, r) \omega_{\zeta^{\prime}}^{2}
$$

where $\Gamma(\theta, r)=\frac{\theta}{1-(1-\theta)(1+r)^{2}}>1$ for $\theta<1$, and

$$
s_{t}-\widehat{s}_{t}=\frac{(1-\theta) \zeta_{t}}{1-(1-\theta)(1+r) \cdot L}-\frac{\theta \xi_{t}}{1-(1-\theta)(1+r) \cdot L}
$$

is the estimation error with $E_{t}\left[s_{t}-\widehat{s}_{t}\right]=0$ and $\operatorname{var}\left(s_{t}-\widehat{s}_{t}\right)=\frac{1-\theta}{1-(1-\theta)(1+r)^{2}} \omega_{\zeta}^{2}$.

\section{General Equilibrium under RI}

\subsection{Optimal Consumption and Savings functions}

Following the standard procedure in the literature, the consumption function and the value function under RI can be obtained by solving the following stochastic Bellman equation:

$$
\widehat{v}\left(\widehat{s}_{t}\right)=\max _{c_{t}}\left\{-\frac{1}{\alpha} \exp \left(-\alpha c_{t}\right)+\frac{1}{1+\rho} E_{t}\left[\widehat{v}\left(\widehat{s}_{t+1}\right)\right]\right\},
$$

subject to (13)-(15). The following proposition summarizes the main results from the above precautionarysavings model with RI.

Proposition 1. For a given Kalman gain, $\theta$, the value function is

$$
\widehat{v}\left(\widehat{s}_{t}\right)=-\frac{1}{r \alpha} \exp \left(-r \alpha\left\{\widehat{s}_{t}-\frac{1}{r \alpha} \ln (1+r)+\frac{1}{r^{2} \alpha}\left[\ln \left(\frac{1+\rho}{1+r}\right)-\ln E_{t}\left[\exp \left(-r \alpha \widehat{\zeta}_{t+1}\right)\right]\right]\right\}\right)
$$

the consumption function is

$$
c_{t}^{*}=r\left\{\widehat{s}_{t}+\frac{1}{\alpha r^{2}}\left[\ln \left(\frac{1+\rho}{1+r}\right)-\ln E_{t}\left[\exp \left(-r \alpha \widehat{\zeta}_{t+1}\right)\right]\right]\right\}
$$

and the saving function is

$$
d_{t}^{*}=\left(1-\phi_{1}\right) \phi\left(y_{t}-\bar{y}\right)+r\left(s_{t}-\widehat{s}_{t}\right)+\frac{1}{r \alpha}\left[\ln E_{t}\left[\exp \left(-r \alpha \widehat{\zeta}_{t+1}\right)\right]-\Psi(r)\right]
$$

where $s_{t}-\widehat{s}_{t}$ is an $M A(\infty)$ estimation error process given in (15) and $\Psi(r)=\ln \left(\frac{1+\rho}{1+r}\right)$. 
Proof. See Appendix 7.1.

Comparing (4) with (18), it is clear that the two consumption functions are identical except that we replace $s_{t}$ with $\widehat{s}_{t}$ and $\zeta_{t+1}\left(\equiv \phi w_{t+1}\right)$ with $\widehat{\zeta}_{t+1}$, respectively. First, given that

$$
\begin{aligned}
\ln E_{t}\left[\exp \left(-r \alpha \zeta_{t+1}\right)\right] & =\frac{1}{2}(r \alpha)^{2} \omega_{\zeta^{\prime}}^{2} \\
\ln E_{t}\left[\exp \left(-r \alpha \widehat{\zeta}_{t+1}\right)\right] & =\frac{1}{2} \Gamma(\theta, r)(r \alpha)^{2} \omega_{\zeta^{\prime}}^{2}
\end{aligned}
$$

it is straightforward to show that the precautionary saving premium due to limited attention is

$$
P_{r i} \equiv \frac{1}{\alpha r} \ln E_{t}\left[\exp \left(-r \alpha \widehat{\zeta}_{t+1}\right)-\exp \left(-r \alpha \zeta_{t+1}\right)\right]=\frac{1}{2}(\Gamma(\theta, r)-1) r \alpha \omega_{\zeta^{\prime}}^{2}
$$

which is clearly decreasing with the degree of attention $(\theta)$, and is increasing with the coefficient of absolute risk aversion $(\alpha)$ and the persistence and volatility of the income shock $(\phi$ and $\sigma)$ for any given $\theta$. In other words, RI can amplify the impact of the interaction of risk aversion and income uncertainty on increasing the amount of precautionary savings.

To further explore the precautionary savings premium in (20), we isolate the effects of RI on individual consumption and saving by rewriting (18) as

$$
c_{t}^{*}=r \widehat{s}_{t}+\frac{1}{r \alpha}\left\{\Psi(r)-\left[\begin{array}{c}
\ln E_{t}\left[\exp \left(-r \alpha \theta(1+r)\left(s_{t}-\widehat{s}_{t}\right)\right)\right]+\frac{1}{2}\left(r \alpha \theta \omega_{\zeta}\right)^{2}+ \\
\frac{1}{2}(1-\theta) \Gamma(\theta, r)\left(r \alpha \omega_{\zeta}\right)^{2}
\end{array}\right]\right\}
$$

where $\Psi(r)=\ln \left(\frac{1+\rho}{1+r}\right)$ measures the relative importance of impatience to the interest rate in determining optimal consumption (it is greater than 0 if $\rho>r$ ),

$$
\frac{1}{\alpha r} \ln E_{t}\left[\exp \left(-\alpha r \theta(1+r)\left(s_{t}-\widehat{s}_{t}\right)\right)\right]=r \alpha \theta(1-\theta) \Gamma(\theta, r)(1+r)^{2} \omega_{\zeta}^{2}
$$

is the precautionary savings premium due to the time $t$ estimation error, $\left(r \alpha \theta \omega_{\zeta}\right)^{2} / 2$ is the precautionary savings premium driven by the exogenous fundamental income shocks $\left\{w_{t}\right\}$, and $(1-\theta) \Gamma(\theta)\left(r \alpha \omega_{\zeta}\right)^{2} / 2$ captures the precautionary savings premium driven by the endogenous noise shocks, $\left\{\xi_{t}\right\} .{ }^{14}$ Note that when $\theta$ converges to 1 , the consumption function with RI, (18), reduces to that of the Wang (2003) model, (4). From (18), for finite capacity $(\kappa<\infty$ or $\theta \in(0,1))$, the precautionary saving premium due to fundamental shocks is lower than that in the full-information case, i.e., $\left(r \alpha \theta \omega_{\zeta}\right)^{2} / 2<$

\footnotetext{
${ }^{14}$ This result is derived by using Equation (15) and the iid property of the processes $\left\{\widehat{\zeta}_{t}\right\},\left\{\zeta_{t}\right\}$, and $\left\{\xi_{t}\right\}$
} 
$\left(r \alpha \omega_{\zeta}\right)^{2} / 2$ because of the incomplete adjustment of consumption to the fundamental shock, while we have two new positive terms that increase the total savings more than the absolute value of the reduced savings: (i) the premium due to the estimation error and (ii) the premium due to the RI-induced endogenous noise.

Given the time $t$ available information and the fact that $E_{t}\left[s_{t}-\widehat{s}_{t}\right]=0$, the conditional mean of (19) can be written as

$$
\widetilde{d}_{t}=f_{t}+\left(\frac{1}{2} r \alpha \Gamma(\theta, r) \omega_{\zeta}^{2}-\frac{1}{r \alpha} \Psi(r)\right)
$$

where the first term $f_{t}=\left(1-\phi_{1}\right) \phi\left(y_{t}-\bar{y}\right)$ captures the consumer's demand for savings "for a rainy day", and the second term, $\frac{1}{2} r \alpha \Gamma(\theta, r) \omega_{\zeta}^{2}$, is the certainty equivalent of the innovation to the perceived state, $\widehat{s_{t}}$.

\subsection{Existence of General Equilibrium}

As in Wang (2003), we assume that the economy is populated by a continuum of ex ante identical, but ex post heterogeneous agents, of total mass normalized to one, with each agent solving the optimal consumption and savings problem with RI specified in (16). Similar to Huggett (1993), the risk-free asset in our model is a pure-consumption loan and is in zero net supply. The initial crosssectional distribution of permanent income is assumed to be the stationary distribution $\Phi(\cdot)$. By the law of large numbers in Sun (2006), provided that the spaces of agents and the probability space are constructed appropriately, aggregate permanent income and the cross-sectional distribution of permanent income $\Phi(\cdot)$ are constant over time.

Proposition 2. The total savings demand "for a rainy day" in the precautionary savings model with RI equals zero for any positive interest rate. That is, $F_{t}(r)=\int_{y_{t}} f_{t}(r) d \Phi\left(y_{t}\right)=0$, for $r>0$.

Proof. The proof uses the LLN and is the same as that in Wang (2003).

Proposition 2 states that the total savings "for a rainy day" is zero, at any positive interest rate. Therefore, from (20), for $r>0$, the expression for total savings under RI in the economy at time $t$ is

$$
D(\theta, r) \equiv \frac{1}{r \alpha}(\Pi(\theta, r)-\Psi(r))=\frac{1}{r \alpha}\left[\frac{1}{2}(r \alpha)^{2} \Gamma(\theta, r) \omega_{\zeta}^{2}-\Psi(r)\right]
$$

where $\Pi(\theta, r)=\frac{1}{2}(r \alpha)^{2} \Gamma(\theta, r) \omega_{\zeta}^{2}$ measures the amount of precautionary savings, and $\Psi(r)$ captures the dissaving effects of impatience. Given (23), an equilibrium under RI is defined by an 
interest rate $r^{*}$ satisfying

$$
D\left(\theta, r^{*}\right)=0 .
$$

The following proposition shows the existence of the equilibrium and the PIH holds in the RI general equilibrium:

Proposition 3. There exists at least one equilibrium with an interest rate $r^{*} \in(0, \rho)$ in the precautionarysavings model with RI. In any such equilibrium, each agent's consumption is described by the PIH, in that

$$
c_{t}^{*}=r^{*} \widehat{s}_{t},
$$

where $\widehat{s}_{t}=E\left[s_{t} \mid \mathcal{I}_{t}\right]$ is the perceived value of permanent income. The evolution equations of wealth and consumption are

$$
\begin{aligned}
\Delta a_{t+1}^{*} & =\frac{1-\phi_{1}}{1+r^{*}-\phi_{1}}\left(y_{t}-\bar{y}\right)+r^{*}\left(s_{t}-\widehat{s}_{t}\right), \\
\Delta c_{t+1}^{*} & =r^{*} \widehat{\zeta}_{t+1},
\end{aligned}
$$

respectively, where $\widehat{\zeta}_{t+1}$ is specified in (14) with $E_{t}\left[\widehat{\zeta}_{t+1}\right]=0, \operatorname{var}\left(\widehat{\zeta}_{t+1}\right)=\Gamma\left(\theta, r^{*}\right) \omega_{\zeta^{\prime}}^{2}$ and $\Gamma\left(\theta, r^{*}\right)=$ $\frac{\theta}{1-(1-\theta)\left(1+r^{*}\right)^{2}}$.

Proof. If $r>\rho$, the two terms, $\Pi(\theta, r)$ and $\Psi(r)$, in the expression for total savings $D\left(\theta, r^{*}\right)$, are positive, which contradicts the equilibrium condition, $D\left(\theta, r^{*}\right)=0$. Since $\Pi(\theta, r)-\Psi(r)<0(>0)$ when $r=0(r=\rho)$, the continuity of the expression for total savings implies that there exists at least one interest rate $r^{*} \in(0, \rho)$ such that $D\left(\theta, r^{*}\right)=0$. From (18), we can obtain the individual's optimal consumption rule under RI in general equilibrium as $c_{t}^{*}=r^{*} \widehat{s}_{t}$. Substituting (25) into (2) yields (26). Using (13) and (25), we can obtain (27).

The intuition behind Proposition 3 is similar to that in Wang (2003). With an individual's constant total precautionary savings demand $\Pi(\theta, r)$, for any $r>0$, the equilibrium interest rate $r^{*}$ must be such that each individual's dissavings demand due to impatience is exactly balanced by their total precautionary-savings demand, $\Pi\left(\theta, r^{*}\right)=\Psi\left(r^{*}\right)$. Figure 1 shows that the aggregate saving function is increasing with the interest rate, and there exists a unique interest rate $r^{*}$ for every given $\theta$ such that $D\left(\theta, r^{*}\right)=0$. Here we choose the parameter values as follows: $\alpha=2.5$, $\phi_{1}=0.88, \sigma=0.29$, and $\rho=0.04 .^{15}$

\footnotetext{
${ }^{15}$ In Section 4.1, we will provide more details about how to estimate the income process using the U.S. data. The main
} 
Given (18) and (24), it is clear that even though the individual increases their total precautionary savings in response to information frictions for a given $r$, the level of aggregate savings equals zero. That is, RI does not affect the aggregate wealth in the economy. In contrast, RI affects the equilibrium interest rate. With lower Shannon channel capacity, the equilibrium interest rate is lower.

From the equilibrium condition,

$$
\frac{1}{2}\left(r^{*} \alpha\right)^{2} \Gamma\left(\theta, r^{*}\right) \omega_{\zeta}^{2}-\ln \left(\frac{1+\rho}{1+r^{*}}\right)=0
$$

it is straightforward to show that

$$
\frac{d r^{*}}{d \theta}=\frac{r^{*}\left(2+r^{*}\right)}{\theta\left[1-(1-\theta)\left(1+r^{*}\right)^{2}\right]}\left\{\begin{array}{c}
\frac{2\left(1-\phi_{1}\right)\left[1-(1-\theta)\left(1+r^{*}\right)\right]+2 r^{*}(1-\theta)\left(1+r^{*}\right)}{r^{*}\left(1+r^{*}-\phi_{1}\right)\left[1-(1-\theta)\left(1+r^{*}\right)^{2}\right]} \\
+\frac{1}{\left(1+r^{*}\right) \ln \left(\frac{1+\rho}{1+r^{*}}\right)}
\end{array}\right\}^{-1}>0,
$$

where $1-(1-\theta)\left(1+r^{*}\right)^{2}>0$ and $\ln \left(\frac{1+\rho}{1+r^{*}}\right)>0$. It is clear from this expression that $r^{*}$ is locally unique and decreasing in the degree of inattention $1-\theta$. Figure 2 illustrates $r^{*}$ as a function of $\theta$ for different values of $\alpha$, and clearly shows that the general equilibrium interest rate is increasing with the degree of attention, $\theta .{ }^{16}$ The first row of Table 1 reports the general equilibrium interest rates for different values of $\theta .{ }^{17}$ We can see from the table that $r^{*}$ decreases as the degree of inattention increases. For example, if $\theta$ is reduced from 1 to $0.2, r^{*}$ is reduced from 2.95 percent to 2.77 percent. One might ask what a reasonable value of $\theta$ is, and whether a drop from 1 to 0.2 is "large" in any sense. Unfortunately, it is not straightforward to answer these questions, so we simply note that 0.2 is larger than the value needed to match portfolio holdings in Luo (2010) and is therefore not obviously unreasonable.

\subsection{Elastic Capacity}

As argued in Sims (2010), instead of using fixed channel capacity to model finite informationprocessing ability, one could assume that the marginal cost of information-processing (i.e., the shadow price of information-processing capacity) is fixed. That is, the Lagrange multiplier on (9) is constant. In the univariate case, the objective of the agent with finite capacity in the filtering problem is to minimize the discounted expected mean square error (MSE), $E_{t}\left[\sum_{t=0}^{\infty} \beta^{t}\left(s_{t}-s_{t}^{*}\right)^{2}\right]$, subject

result here is robust to the choices of these parameter values.

${ }^{16}$ Here we use the same parameter values as above. For different values of $\sigma$ and $\phi_{1}$, we have the similar pattern of the equilibrium interest rate as in the benchmark case.

${ }^{17}$ Here we also set $\gamma=2.5, \phi_{1}=0.88, \sigma=0.29$, and $\rho=0.04$. 
to the information-processing constraint, or

$$
\min _{\left\{\Sigma_{t}\right\}}\left\{\sum_{t=0}^{\infty} \beta^{t}\left[\Sigma_{t}+\lambda \ln \left(\frac{(1+r)^{2} \Sigma_{t-1}+\omega_{\zeta}^{2}}{\Sigma_{t}}\right)\right]\right\}
$$

where $\Sigma_{t}$ is the conditional variance at $t, \lambda$ is the Lagrange multiplier corresponding to (9). Solving this problem yields the optimal steady state conditional variance:

$$
\Sigma=\frac{(1+r)^{2}(1-\beta) \tilde{\lambda}-1+\sqrt{\left[(1+r)^{2}(1-\beta) \tilde{\lambda}-1\right]^{2}+4 \widetilde{\lambda}(1+r)^{2}}}{2(1+r)^{2}} \omega_{\zeta^{\prime}}^{2}
$$

where $\widetilde{\lambda}=\lambda / \omega_{\zeta}^{2}$ is the normalized shadow price of information-processing capacity. It is straightforward to show that as $\lambda$ goes to $0, \Sigma=0$; and as $\lambda$ goes to $\infty, \Sigma=\infty$. Note that $\frac{\partial \ln \Sigma}{\partial \ln \omega_{\zeta}^{2}}<1$ if we adopt the assumption that $\lambda$ is fixed, while $\frac{\partial \ln \Sigma}{\partial \ln \omega_{\zeta}^{2}}=1$ in the fixed $\kappa$ case. Comparing (30) with (10), it is clear that the two RI modeling strategies are observationally equivalent in the sense that they lead to the same conditional variance if the following equality holds:

$\kappa(r, \tilde{\lambda})=\ln (1+r)+\frac{1}{2} \ln \left(1+\frac{2}{(1+r)^{2}(1-\beta) \tilde{\lambda}-1+\sqrt{\left[(1+r)^{2}(1-\beta) \tilde{\lambda}-1\right]^{2}+4 \tilde{\lambda}(1+r)^{2}}}\right)$.

In this case, the Kalman gain is

$$
\theta(r, \tilde{\lambda})=1-\frac{1}{1+r}\left\{1+\frac{2}{(1+r)^{2}(1-\beta) \widetilde{\lambda}-1+\sqrt{\left[(1+r)^{2}(1-\beta) \tilde{\lambda}-1\right]^{2}+4 \widetilde{\lambda}(1+r)^{2}}}\right\}^{-1} .
$$

It is obvious that $\mathcal{\kappa}$ converges to its lower limit $\underline{\kappa}=\ln (1+r) \approx r$ as $\lambda$ goes to $\infty$; and it converges to $\infty$ as $\lambda$ goes to 0 . In other words, using this RI modeling strategy, the consumer is allowed to adjust the optimal level of capacity in such a way that the marginal cost of information-processing for the problem at hand remains constant. Note that this result is consistent with the concept of 'elastic' capacity proposed in Kahneman (1973).

Given this relationship between $\lambda$ and $\theta$ (or $\kappa$ ), in the following analysis we just use the value of $\theta$ to measure the degree of attention. It is worth noting that although the above two RI modeling strategies, inelastic and elastic capacity, are observationally equivalent in the "static" sense, 
they have distinct implications for the model's propagation mechanism if the economy is experiencing regime switching (e.g., before and after the great moderation). With inelastic capacity, the propagation mechanism governed by the Kalman gain is fixed regardless of changes in fundamental uncertainty, while with elastic capacity the propagation mechanism will change in response to changes in fundamental uncertainty.

The key difference between the elastic capacity case and the fixed capacity case is that $\kappa$ and $\theta$ now depend on both the equilibrium interest rate and labor income uncertainty for a given $\lambda$. The equilibrium interest rate is now determined implicitly by the following function:

$$
D\left(\theta\left(r^{*}, \widetilde{\lambda}\right), r^{*}\right) \equiv \frac{1}{r^{*} \alpha}\left[\frac{1}{2}\left(r^{*} \alpha\right)^{2} \Gamma\left(\theta\left(r^{*}, \widetilde{\lambda}\right), r^{*}\right) \omega_{\zeta}^{2}-\ln \left(\frac{1+\rho}{1+r^{*}}\right)\right]=0
$$

Figure 3 illustrates how $r^{*}$ varies with labor income uncertainty, $\sigma$, for fixed information-processing cost, $\lambda$. It clearly shows that the aggregate saving function is increasing with the interest rate and the general equilibrium interest rate is decreasing with labor income uncertainty. We can see from Table 2 that when the economy becomes more volatile (i.e., larger $\sigma$ ), the Kalman gain $(\theta)$ increases while the equilibrium interest rate $\left(r^{*}\right)$ decreases. This result is different from that obtained in the fixed capacity case in which $\theta$ and $r^{*}$ move in the same direction. (See Table 1.) The main reason for this result is that income uncertainty affects the equilibrium interest rate via two channel: (i) the direct channel which leads to higher aggregate savings (i.e., the $\omega_{\zeta}^{2}$ term in (33)) and (ii) the indirect channel which leads to lower aggregate savings (i.e., the $\theta\left(r^{*}, \widetilde{\lambda}\right)$ term in (33)), and the direct channel dominates.

\subsection{Comparison with Habit Formation}

Habit formation (HF) has been widely used in economic models to study the consumption and saving behavior and asset pricing. It can be modelled directly as a structure of preferences in which psychological factors make consumers prefer to gradual adjustment in consumption, thereby consumption volatility is more painful than it would be in the absence of habit persistence. As shown in Luo (2008) within a partial equilibrium PIH framework, the key difference between HF and RI is that individual consumption under RI reacts not only to income shocks but also to its own endogenous noises induced by finite capacity. In other words, although the two models lead to the same response of consumption to income shocks, consumption growth under RI is more volatile than that under habit formation at the individual level because the noise terms due to RI also contribute to the relative volatility of consumption. In contrast, the effects of HF and RI on aggregate consump- 
tion could be similar because aggregating across all individuals would weaken or even eliminate the impacts of the endogenous noises on consumption growth. ${ }^{18}$

In this section, we compare the different implications of HF and RI in the general equilibrium framework. Following Alessie and Lusardi (1997), we introduce HF into the FI-RE model specified in Section 2.1 by assuming that the utility function takes the following form:

$$
u\left(c_{t}, c_{t-1}\right)=-\frac{1}{\alpha} \exp \left(-\alpha\left(c_{t}-\gamma c_{t-1}\right)\right)
$$

Using the same solution method used in Section 2.1, we can solve for the consumption function under HF:

$$
c_{t}=\frac{r(1+r-\gamma)}{1+r} s_{t}+\frac{\gamma}{1+r} c_{t-1}+\frac{1}{r \alpha}\left(\ln \left(\frac{1+\rho}{1+r}\right)-\ln E_{t}\left[\exp \left(-\frac{\alpha r(1+r-\gamma)}{1+r} \zeta_{t+1}\right)\right]\right) ;
$$

see Appendix 7.2 for the derivation. The corresponding saving function can thus be written as

$d_{t}=\left(1-\phi_{1}\right) \phi\left(y_{t}-\bar{y}\right)+\frac{r^{2} \gamma}{1+r} \frac{\zeta_{t}}{1-\gamma \cdot L}-\frac{1}{\alpha(1-\gamma)}\left(\ln \left(\frac{1+\rho}{1+r}\right)-\ln E_{t}\left[\exp \left(-\frac{r \alpha(1+r-\gamma)}{1+r} \zeta_{t+1}\right)\right]\right)$.

Following the same definition of general equilibrium in our benchmark model, it is straightforward to show that there exists an equilibrium interest rate $r^{*}$ such that:

$$
\ln \left(\frac{1+\rho}{1+r^{*}}\right)-\frac{1}{2}\left(r^{*} \alpha\right)^{2} \widetilde{\Gamma}\left(\gamma, r^{*}\right) \omega_{\zeta}^{2}=0
$$

where $\widetilde{\Gamma}\left(\gamma, r^{*}\right)=\left(\frac{1+r^{*}-\gamma}{1+r^{*}}\right)^{2}<1$, and

$$
\frac{d r^{*}}{d \gamma}<0
$$

That is, the stronger the habit persistence, the higher the equilibrium interest rate. ${ }^{19}$ In summary, we can conclude that although both RI and HF lead to slow adjustments in consumption, they have opposite impacts on the equilibrium interest rate. ${ }^{20}$ RI reduces the equilibrium interest rate, while

\footnotetext{
${ }^{18}$ Reis (2006) showed that infrequent adjustments due to inattentiveness also leads to gradual responses of aggregate consumption to income shocks, which matches the empirical evidence. See Luo (2008) for a discussion on Sims' rational inattention hypothess and Reis' inattentiveness hypothesis.

${ }^{19}$ In a partial equilibrium model, Alessie and Lusardi (1997) show that the stronger the habit, the less impact of income uncertainty on the precautionary saving term.

${ }^{20}$ It is worth noting that the mechanisms of RI and HF that generate slow adjustment are distinct. Under RI, slow adjustment is forced upon the agent due to finite information processing capacity (learning is slow). In contrast, slow adjustment is optimal under FI because consumers are assumed to prefer to smooth not only consumption but also consumption growth.
} 
HF increases it.

\section{Quantitative Results}

In this section we assess our GE-RI model's implications for consumption and income dynamics. We first construct time series for the cross-sectional dispersons of consumption and income, using the imputation approach from Blundell, Pistaferri, and Preston (2008) and Guvenen and Smith (2014). Our central finding here is that consumption "inequality" declined during the 1980s but then flattened out relative to income. We then use our model to assess how changes in attention might have played a role in contributing to this decline, given the movements in the volatility of income. $^{21}$

\subsection{Empirical Evidence}

In order to measure the relative consumption dispersion in the data, $\frac{\mathrm{sd}(\Delta c)}{\mathrm{sd}(\Delta y)}$, we construct a panel data set which contains both consumption and income at the household level. We also use this panel to estimate the household income process. As panel data for consumption generally are not available, we first describe how we construct a consumption panel based on the Panel Study of Income Dynamics (PSID) and the Consumer Expenditure Survey (CEX).

Following Blundell, Pistaferri, and Preston (2008), we define the household income as total household income (including wage, financial, and transfer income of head, wife, and all others in household) minus financial income (defined as the sum of annual dividend income, interest income, rental income, trust fund income, and income from royalties for the head of the household only) minus the tax liability of non-financial income. This tax liability is defined as the total tax liability multiplied by the non-financial share of total income. Tax liabilities after 1992 are not reported in the PSID and so we estimate them using the TAXSIM program from the National Bureau of Economic Research. Our final household income measure can be expressed as:

income measure $=($ total $\mathrm{HH}$ income - financial income $)-$ taxes $\times \frac{\text { total } \mathrm{HH} \text { income }- \text { financial income }}{\text { total } \mathrm{HH} \text { income }}$.

The PSID does not include enough consumption expenditure data to create full picture of household nondurable consumption. Such detailed expenditures are found, though, in the CEX from the Bureau of Labor Statistics. But households in this study are only interviewed for four consecutive

\footnotetext{
${ }^{21}$ Other mechanisms have been proposed for this decline; see Krueger and Perri (2006) and Athreya, Tam, and Young (2009) for examples.
} 
quarters and thus do not form a panel. To create a panel of consumption to match the PSID income measures, we use an estimated demand function for imputing nondurable consumption created by Guvenen and Smith (2014). Using an IV regression, they estimate a demand function for nondurable consumption that fits the detailed data in the CEX. The demand function uses demographic information and food consumption which can be found in both the CEX and PSID. Thus, we use this demand function of food consumption and demographic information (including age, family size, inflation measures, race, and education) to estimate nondurable consumption for PSID households, creating a consumption panel.

Our household sample selection closely follows that of Blundell, Pistaferri, and Preston (2008) as well. ${ }^{22}$ We exclude households in the PSID low-income and Latino samples. We exclude household incomes in years of family composition change, divorce or remarriage, and female headship. We also exclude incomes in years where the head or wife is under 30 or over 65 , or is missing education, region, or income responses. We also exclude household incomes where non-financial income is less than $\$ 1000$, where year-over-year income change is greater than $\$ 90,000$, and where year-over-year consumption change is greater than $\$ 50,000$. Our final panel contains 7,220 unique households with 54,901 yearly income responses and 50,422 imputed nondurable consumption values. ${ }^{23}$

With this constructed panel of household income and consumption, Figure 4 shows the relative dispersion of consumption, defined as the ratio of the standard deviation of the consumption change to the standard deviation of the income change between 1980 and 2000. The basic pattern confirms but extends the findings in Blundell et al. (2008) - relative consumption dispersion declines in the 1980s, but this decline stops around 1990. Based on our theoretic model, we are able to quantify the contribution of rational inattention to this decline.

In order to estimate the income process, we narrow the sample period to the years 1980 - 1996, due to the PSID survey changing to a biennial schedule after 1996. To further restrict the sample to exclude households with dramatic year-over-year income and consumption changes, we eliminate household observations in years where either income or consumption has increased more than 200 percent or decreased more than 80 percent from the previous year. Following Floden and Lindé

\footnotetext{
${ }^{22}$ They create a new panel series of consumption that combines information from PSID and CEX, focusing on the period when some of the largest changes in income inequality occurred. For other explanations for observed consumption and income inequality, see Krueger and Perri (2006) and Attanasio and Pavoni (2012).

${ }^{23}$ There are more household incomes than imputed consumption values because food consumption - the main input variable in Guvenen and Smith's nondurable demand function - is not reported in the PSID for the years 1987 and 1988. Dividing the total income responses by unique households yields an average of $7-8$ years of responses per household. These years are not necessarily consecutive as our sample selection procedure allows households to be excluded in certain years but return to the sample if they later meet the criteria once again.
} 
(2001), we normalize household income measures as ratios of the mean for that year. We then exclude all household values in years in which the income is less than 10 percent of the mean for that year or more than ten times the mean. To eliminate possible heteroskedasticity in the income measures, we follow Floden and Lindé (2001) and regress each on a series of demographic variables to remove variation caused by differences in age and education. We next subtract these fitted values from each measure to create a panel of income residuals. We then use this panel to estimate the household income process as specified by equation (3) by running panel regressions on lagged income. The estimated values of $\phi_{0}, \phi_{1}$, and $\sigma$ are $0.0006,0.88$, and 0.29 , respectively.

\subsection{Empirical Implications for the Dynamics of Consumption, Wealth, and Income}

Luo (2008) examines how RI affects consumption volatility in a partial equilibrium version of the PIH model presented above. In general equilibrium, since RI affects the equilibrium interest rate via interacting with the coefficient of absolute risk aversion and income uncertainty, it will have an additional effect on consumption dynamics. Using (26) and (27), we can obtain the key stochastic properties of the joint dynamics of individual consumption, income, and saving. The following proposition summarizes the implications of RI for the relative volatility of consumption to income as well as the relative volatility of financial wealth to income:

Proposition 4. Under RI, the relative volatility of individual consumption growth to income growth is

$$
\mu_{c y} \equiv \frac{s d\left(\Delta c_{t}^{*}\right)}{s d\left(\Delta y_{t}\right)}=\phi r^{*} \sqrt{\frac{\left(1+\phi_{1}\right) \Gamma\left(\theta, r^{*}\right)}{2}}
$$

and the relative volatility of financial wealth to income is

$$
\mu_{a y} \equiv \frac{s d\left(\Delta a_{t}^{*}\right)}{s d\left(\Delta y_{t}\right)}=\frac{1}{\sqrt{2}\left(1+r^{*}-\phi_{1}\right)} \sqrt{1-\phi_{1}+\frac{\left(r^{*}\right)^{2}(1-\theta)\left(1+\phi_{1}\right)}{1-\left(1+r^{*}\right)^{2}(1-\theta)}+\frac{2 r^{*}(1-\theta)\left(1-\phi_{1}^{2}\right)}{1-\phi_{1}(1-\theta)\left(1+r^{*}\right)}}
$$

Proof. See Online Appendix.

Expression (38) shows that RI has two opposing effects on consumption volatility. The first effect is direct through its presence in the expression of $\Gamma\left(\theta, r^{*}\right)$, whereas the second effect is through the general equilibrium interest rate $\left(r^{*}\right)$ and is thus indirect. Using the expression of $\Gamma\left(\theta, r^{*}\right)$, it is straightforward to show that the direct effect of RI is to increase consumption volatility. The intuition is very simple: the presence of the RI-induced noise dominates the slow adjustment of consumption in determining consumption volatility at the individual level. In contrast, the indirect 
effect of RI will reduce consumption volatility because it reduces the general equilibrium interest rate and $\partial \Gamma\left(\theta, r^{*}\right) / \partial r^{*}>0$. Following the literature of precautionary savings and the estimated income process in the preceding subsection, we set $\rho=0.04, \alpha=2.5, \sigma=0.29$, and $\phi_{1}=0.88$. The second to fourth rows of Table 1 reports how the interest rate and the relative volatility of consumption and wealth to income vary with $\theta$ in general equilibrium. It is clear from the second row of Table 1 that RI can significantly affect the equilibrium interest rate. For example, when $\theta$ decreases from 1 to $0.1, r^{*}$ decreases from $2.95 \%$ to $2.51 \%$. From the third row of Table 1 , the relative volatility of consumption growth to income growth increases with the degree of inattention. For example, when $\theta$ decreases from $100 \%$ to $10 \%, \mu_{c y}$ increases from 0.191 to 0.227 . That is, the direct effect of inattention via the $\Gamma\left(\theta, r^{*}\right)$ term dominates its indirect general equilibrium effect via $r^{*}$. We can get the same conclusion by shutting down the general equilibrium (GE) channel, see the corresponding partial equilibrium (PE) results reported in the same table. Comparing the GE and PE results in Table 1, we can see the values of $\mu_{c y}$ are slightly lower in the GE case if the interest rate is fixed as $\theta$ decreases. In other words, the general equilibrium effect of RI tends to reduce the volatility of individual consumption in this case. ${ }^{24}$

Another important implication of RI in general equilibrium is that RI leads to more skewed wealth inequality measured by $\mu_{a y}$, the relative volatility of financial wealth to labor income. From the fourth row of Table 1, we can see that when $\theta$ is reduced from 1 to $0.1, \mu_{a y}$ increases from 1.639 to 2.145. From (26), it is clear that the main driving force behind this result is the presence of the estimation error, $s_{t}-\widehat{s}_{t}$ because $\partial \operatorname{var}\left(s_{t}-\widehat{s}_{t}\right) / \partial \theta<0$. Note that although $\partial r^{*} / \partial \theta>0$, the estimation error channel dominates the general equilibrium channel and raises the wealth inequality. Therefore, RI can increase wealth inequality, which makes the model fit the data better. ${ }^{25}$

Table 2 reports how elastic Kalman gain, the general equilibrium interest rate, and the relative volatility of consumption and wealth to income for different values of $\sigma$. It is clear from the second row of Table 2 that the Kalman gain increases with income volatility. For example, if $\lambda=50, \theta$ is almost doubled when $\sigma$ increases from 0.2 to 0.4 . From the third row of Table 2, we can see that RI has significant effects on the equilibrium interest rate. For example, $r^{*}$ decreases from $3.184 \%$ to $2.402 \%$ when $\sigma$ increases from 0.2 to 0.4 . It is worth noting that in the elastic capacity case an

\footnotetext{
${ }^{24}$ We cannot examine the stochastic properties of aggregate consumption dynamics because all idiosyncratic shocks (income shocks and RI-induced noise shocks) cancel out after aggregating aross consumers.

${ }^{25}$ The literature has typically found that simple models based on standard CRRA preferences and on uninsurable shocks to labor income cannot account for the observed U.S. wealth distribution. For example, Aiyagari (1994) finds considerably less wealth concentration in a model with only idiosyncratic labor earnings uncertainty. Given the CARAGaussian setting, the model here is not suitable to address the issue like why the top 1 percent or 5 percent richest families hold a large fraction of financial wealth in the U.S. economy.
} 
increase in income volatility affects the equilibrium interest rate via two channels: (i) the direct channel (the $\omega_{\zeta}^{2}$ term in (33)) and (ii) the indirect channel (the elastic capacity $\theta$ term in (33)). The second panel of Table 2 reports the results when we shut down the indirect channel and assume that $\theta=1$. Comparing the third and sixth rows of Table 2 , we can see that the indirect channel is more important when $\sigma$ is relatively low. For example, given that $\sigma=0.1, r^{*}$ decreases from $3.811 \%$ to $3.528 \%$ when we switch from the FI economy to the RI economy. Furthermore, the relative volatility of consumption growth to income growth decreases with the value of $\sigma$ in general equilibrium. That is, consumption becomes smoother when income becomes more volatile. For example, in the equilibrium RI economy, $\mu_{c y}$ decreases from 0.243 to 0.171 when $\sigma$ is doubled from 0.2 to $0.4 .^{26}$ This result is consistent with our observations on consumption inequality.

To further explore this issue in our model, we do the following exercise. First, we divide the full sample into two sub-samples (1980 - 1986 and 1987 - 1996; or 1980 - 1987 and 1988 - 1996) and apply the same estimation procedure to re-estimate $\sigma$ and $\phi_{2}$ (see Table 3 for the estimation results). Household income is more volatile in late sub-periods than earlier ones. For example, the standard deviation of $y$ is 0.47 in the sub-sample $(1980-1986)$, while it is 0.59 in the sub-sample $(1987-1996)$. The average values of $\mu_{c y}$ are 0.2447 and 0.1919 in the first and second sub-samples, respectively. In the elastic capacity case, using the estimated income processes in the first sub-sample, we first use $\mu_{c y}=0.245$ to calibrate that $\lambda=365$. Using this calibrated value of $\lambda$, we find that $\mu_{c y}=0.196$, which matches the empirical counterpart almost perfectly. ${ }^{27}$

\subsection{Welfare Losses due to RI in Equilibrium}

We now turn to the welfare cost of RI - how much utility does a consumer lose if the actual consumption path he chooses under RI deviates from the first-best FI-RE path in which $\theta=1$ ? To answer this question, we follow Barro (2007) and Luo and Young (2010) by computing the marginal welfare cost due to RI. The following proposition summarizes the main result/

Proposition 5. Given the initial value of the state, $\widehat{s}_{0}$, the marginal welfare cost (mwc) due to RI is given by

$$
\operatorname{mwc}(\theta) \equiv \frac{\left(\partial v\left(\widehat{s}_{0}\right) / \partial \theta\right) \theta}{\left(\partial v\left(\widehat{s}_{0}\right) / \partial \widehat{s}_{0}\right) \widehat{s}_{0}}=\frac{\theta}{r^{* 2} \alpha}\left[r^{*} \alpha+\frac{1}{\left(1+r^{*}\right) \widehat{s}_{0}}\right] \frac{d r^{*}}{d \theta}
$$

where $d r^{*} / d \theta$ is given in (29) and $\widehat{v}\left(\widehat{s}_{0}\right)=-\exp \left(-r^{*} \alpha \widehat{s}_{0}+\ln \left(1+r^{*}\right)\right) /\left(r^{*} \alpha\right)$. The monthly dollar loss

\footnotetext{
${ }^{26}$ It is not surprising that $\mu_{c y}$ is greater in the equilibrium RI economy than in the equilibrium FI economy because the value of $\theta$ is less than 1 in the RI case. This result is the same as that we obtained in the fixed capacity case and reported in Table 1.

${ }^{27}$ Choosing another sub-samples (1980 - 1987 and 1988 - 1996) does not change our main result.
} 
due to deviating from the FI-RE path $(\theta=1)$ can be written as

$$
\$ \operatorname{loss}(\theta<1) \equiv \frac{1}{12} r^{*} \operatorname{mwc}(1)(1-\theta) \widehat{s}_{0} .
$$

Proof. See Appendix 7.3. Since we are interested in the deviation from the FI-RE path, $\theta=1$ is considered as the starting point. When the household deviates from 1 to $\theta$, the percentage change in just $(\theta-1) . \widehat{s}_{0}$ is initial total wealth. Finally, we need to convert the change in the $\widehat{s}_{0}$ term to monthly rates by multiplying by $r^{*} / 12$.

Expression (40) gives the proportionate reduction in the initial level of the perceived state $\left(\widehat{s}_{0}\right)$ that compensates, at the margin, for a percentage decrease in $\theta$ (i.e., stronger degree of RI) - in the sense of preserving the same effect on welfare for a given $\widehat{s}_{0}$. To do quantitative welfare analysis we need to know the value of $\widehat{s}_{0}$. First, we set $\widehat{y}_{0} \equiv E\left[y_{t}\right]=1, \phi_{1}=0.88$, and the ratio of the initial level of financial wealth $\left(\widehat{a}_{0}\right)$ to mean income $\left(\widehat{y}_{0}\right)$ equal to $5 .{ }^{28}$ Second, given that $\widehat{s}_{0}=$ $\widehat{a}_{0}+\widehat{y}_{0} /\left(1+r^{*}-\phi_{1}\right)+\widehat{y}_{0} / r^{*}=\left[5+1 /\left(1+r^{*}-\phi_{1}\right)+1 / r^{*}\right] \widehat{y}_{0}$, we can calculate the values of the monthly dollar loss (\$loss) for different values of $\theta$ and the corresponding values of the general equilibrium interest rate. The fifth row of Table 1 reports the welfare losses for different degrees of inattention. For example, when $\theta=0.4$, i.e., when the household deviate from the FI-RE path by $60 \%$, the monthly dollar loss is $6.040 \times 10^{-4} \times \widehat{y}_{0}$, whereas it decreases to $3.025 \times 10^{-4} \times \widehat{y}_{0}$ when $\theta=0.8 .^{29}$

Another implication of the welfare losses due to RI reported in Table 1 is that there is a general equilibrium effect of RI on the welfare loss. For example, when $r$ is set to be $2.95 \%$ in the PE case, the monthly dollar loss is larger than that obtained in the GE case for low values of $\theta$. For example, when $\theta=0.1$, the welfare loss in the GE case is 3.57 percent lower than that in the PE case. Thus, the partial equilibrium results might overstate the welfare losses. These two results thus provide some evidence that it is reasonable for consumers to learn the true state slowly due to finite capacity because the welfare loss from deviating from the FI-RE case is trivial. In other words, although consumers could devote much more capacity to processing economic information and thus improve their consumption decisions, it may be rational for them not to do so even when information costs are negligible.

\footnotetext{
${ }^{28}$ This number varies largely for different individuals, from 2 to 20.5 is the average wealth/income ratio in the Survey of Consumer Finances 2001. We find that changing the value of this ratio only has minor effects on the welfare implication.

${ }^{29}$ The main conclusion here is robust to changes in the values of $\alpha, \sigma$, and $\phi_{1}$.
} 


\section{Separation of Risk Aversion and Intertemporal Substitution}

In this section, we consider an extension in which we assume that consumers have recursive utility and thus risk aversion and intertemporal substitution are controlled by different parameters. In our benchmark model, we discussed how the interaction of risk aversion and intertemporal substitution affects the equilibrium interest rate and the relative volatility of consumption. However, given the time-separable utility setting, we cannot examine how intertemporal substitution affects the equilibrium outcomes. In this section, we consider a recursive utility (RU) model with iso-elastic intertemporal substitution and exponential risk aversion proposed in Weil (1993):

$$
U_{t}=\left[(1-\beta) c_{t}^{\frac{\eta-1}{\eta}}+\beta\left(-\frac{1}{\alpha} \ln E_{t}\left[\exp \left(-\alpha U_{t+1}\right)\right]\right)^{\frac{\eta-1}{\eta}}\right]^{\frac{\eta}{\eta-1}}
$$

where $\beta>0$ is the agent's subjective discount factor, $\alpha>0$ is the coefficient of absolute risk aversion, and $\eta>0$ is the elasticity of intertemporal substitution. Following the same state-space-reduction method, the Bellman equation for the optimization problem in the Weil model can be written as:

$$
v\left(s_{t}\right)=\max _{\left\{c_{t}\right\}}\left\{(1-\beta) c_{t}^{\frac{\eta-1}{\eta}}+\beta\left(-\frac{1}{\alpha} \ln E_{t}\left[\exp \left(-\alpha v\left(s_{t+1}\right)\right)\right]\right)^{\frac{\eta-1}{\eta}}\right\}^{\frac{\eta}{\eta-1}},
$$

where $s_{t} \equiv a_{t}+\phi y_{t}+\phi_{0} \phi / r, \phi=1 /\left(1+r-\phi_{1}\right)$, and $s_{t}$ follows the same state transition equation, (6). As shown in Weil (1993), the consumption function under FI-RE can be expressed as:

$$
c_{t}=(1+r-\delta)\left(s_{t}-\frac{1}{r \alpha A} \ln \left(E_{t}\left[\exp \left(-\alpha \varphi a \sigma w_{t+1}\right)\right]\right)\right)
$$

where $A=\left(1+r-\delta^{\frac{1}{\eta}}\right)^{\frac{\eta}{\eta-1}}(1+r-\delta)^{\frac{1}{1-\eta}}$ and $\delta=(\beta(1+r))^{\eta}$.

\subsection{Consumption and Saving Rules under RI}

As in the benchmark model, we now introduce RI. The corresponding Bellman equation under RI can be written as

$$
v\left(\widehat{s}_{t}\right)=\max _{\left\{c_{t}\right\}}\left\{(1-\beta) c_{t}^{\frac{\eta-1}{\eta}}+\beta\left(-\frac{1}{\alpha} \ln \left(E_{t}\left[\exp \left(-\alpha v\left(\widehat{s}_{t+1}\right)\right)\right]\right)\right)^{\frac{\eta-1}{\eta}}\right\}^{\frac{\eta}{\eta-1}},
$$


subject to the transition equation of $\widehat{s}_{t},(13)$. The following proposition characterizes the consumption function and value function under RI.

Proposition 6. Given finite capacity $\kappa$, the consumption function under RI is

$$
c_{t}^{*}=(1+r-\delta)\left(\widehat{s}_{t}-\frac{1}{r} \varepsilon^{*}\right)
$$

where

$$
\varepsilon^{*}=\frac{1}{\alpha A} \ln \left(E_{t}\left[\exp \left(-\alpha A \widehat{\zeta}_{t+1}\right)\right]\right),
$$

$A$ and $\delta$ are defined above, and $\widehat{\zeta}_{t+1}$ is specified in (14) with $E_{t}\left[\widehat{\zeta}_{t+1}\right]=0, \operatorname{var}\left(\widehat{\zeta}_{t+1}\right)=\Gamma(\theta, r) \omega_{\zeta^{\prime}}^{2}$ and $\Gamma(\theta, r)=\frac{\theta}{1-(1-\theta)(1+r)^{2}}$.

Proof. See Appendix 7.4.

When $\beta=1 /(1+r)$, we have $\delta=1, A=r$, and the RU model is reduced to our benchmark model. In contrast, when $\beta \neq 1 /(1+r), A \geq r$ is increasing with $\eta$ for given $r$ (see Figure 5). Comparing (42) with (43), it is clear that (43) can be obtained by replacing $s_{t}$ and $\zeta_{t+1}$ in (42) with $\widehat{s}_{t}$ and $\widehat{\zeta}_{t+1}$, respectively. First, given that

$$
\begin{aligned}
\ln \left(E_{t}\left[\exp \left(-A \alpha \zeta_{t+1}\right)\right]\right) & =\frac{1}{2}(\alpha A)^{2} \omega_{\zeta^{\prime}}^{2} \\
\ln \left(E_{t}\left[\exp \left(-A \alpha \widehat{\zeta}_{t+1}\right)\right]\right) & =\frac{1}{2} \Gamma(\theta, r)(\alpha A)^{2} \omega_{\zeta^{\prime}}^{2}
\end{aligned}
$$

the precautionary saving premium due to RI can be written as

$$
P_{r i}=\frac{1}{2}(\Gamma(\theta, r)-1) \alpha A \omega_{\zeta}^{2}
$$

which clearly shows that the premium is decreasing with the degree of attention $\theta$, and is increasing with the degree of risk aversion $\alpha$, the elasticity of intertemporal substitution $\eta$, and the persistence and volatility of the income shock ( $\phi$ and $\sigma$ ) for any value of $\theta$.

Using (43), we can express the saving function as follows:

$$
d_{t}^{*}=f_{t}-\Theta_{t}-\Psi_{t}+\Pi,
$$


where $f_{t}=\left(1-\phi_{1}\right) \phi\left(y_{t}-\bar{y}\right), \Theta_{t} \equiv(1+r-\delta)\left(\widehat{s}_{t}-s_{t}\right), \Psi_{t}=\Psi_{1, t}+\Psi_{2}$,

$$
\Psi_{1, t} \equiv(1-\delta)\left(s_{t}-\bar{s}\right), \Psi_{2} \equiv(1-\delta) \bar{s},
$$

and $\Pi \equiv(1+r-\delta) \varepsilon^{*} / r$. Here $f_{t}$ captures the consumer's demand for savings "for a rainy day", $\Theta_{t}$ captures the RI-induced savings, and $\Psi_{t}$ captures the dissaving effect due to relative impatience, which is affine in the value of total resources, $s_{t} \cdot{ }^{30}$ It is worth noting that this part of saving measures consumers' intertemporal consumption smoothing motive, and is independent of the degree of risk aversion and labor income uncertainty. Unlike the benchmark model with the time-additive utility, in the RU case the $\Psi_{t}$ term increases with the value of total wealth $\left(s_{t}\right)$ when the consumers are relatively more impatient, i.e., $\delta=(\beta(1+r))^{\eta}<1$. This result is consistent with that obtained in Wang (2007) in which the dissaving effect is generated by the endogenous discount factor. In addition, the $\Psi_{t}$ term can also capture the intuition that richer consumers are more impatient and thus dissave more in the steady state used to model the endogenous discount factor.

\subsubsection{General Equilibrium Implications}

Using the individual saving function (46) and following the same aggregation procedure used in the previous section, we have the following result on the total saving demand.

Proposition 7. Both the total demand of savings "for a rainy day", the total demand for the RI-induced estimation-errors savings equal zero for any positive interest rate. That is,

$$
F_{t}(r)=\int_{y_{t}} f_{t}(r) d \Phi\left(y_{t}\right)=0 G_{t}(r)=\int_{s_{t}} \Theta_{t} d \Phi_{\widehat{s}_{t}-s_{t}}\left(\widehat{s}_{t}-s_{t}\right)=0
$$

and

$$
H_{t}(r)=\int_{s_{t}} \Psi_{1, t} d \Phi_{s}\left(s_{t}\right)=0
$$

for $r>0$.

Proof. The proof uses the LLN and is the same as that in Wang (2003).

Furthermore, from (46), after aggregating across all consumers, the expression for total savings

\footnotetext{
${ }^{30}$ Note that $\Psi_{1, t}$ is a mean reverting process and $\Psi_{2}$ is a constant term. See Appendix 7.4 for the derivation.
} 
in this RU model can be written as:

$$
D(r) \equiv \Pi(r)-\Psi_{2}(r),
$$

where the first term measures the amount of precautionary savings due to risk aversion, intertemporal substitution, and inattention, and the second term captures the steady state dissavings effects of impatience. As in the benchmark model, we define the equilibrium in our model as: $D\left(r^{*}\right)=0$. The following proposition shows the existence of the equilibrium and the PIH holds in the general equilibrium.

Proposition 8. There exist multiple equilibria (multiple $\left.r^{*}\right)$ in the RU-RI model. In any equilibrium, each consumer's optimal consumption is described by the PIH, in that

$$
c_{t}^{*}=r^{*} \widehat{s}_{t}+(1-\delta)\left(\widehat{s}_{t}-\bar{s}\right) \text { or } c_{t}^{*}=r^{*} s_{t}+\Theta_{t}+\Psi_{1, t}
$$

and $E\left[c_{t}^{*}\right]=r^{*} E\left[\widehat{s}_{t}\right]=r^{*} E\left[s_{t}\right]=r^{*} \bar{s}$.

Proof. Because both $\bar{c}=(1+r-\delta)\left(\bar{s}-\frac{1}{r} \varepsilon^{*}\right)$ and $\bar{c}=r^{*} \bar{s}$ hold in the steady state, we can obtain that $\bar{s}=\frac{1+r-\delta}{r(1-\delta)} \varepsilon^{*}$, which implies that $D\left(r^{*}\right) \equiv \Gamma\left(r^{*}\right)-\Psi_{2}\left(r^{*}\right)=0$ for any $r^{*}$.

It is worth noting that in the steady state equilibrium, the constant dissaving effect measured by $\Psi_{2}$ is exactly offset by the precautionary saving effect due to the interaction of income uncertainty, risk aversion, and intertemporal substitution.

\section{Concluding Remarks}

In this paper we have studied how rational inattention affects the interest rate and the joint dynamics of consumption and income in a Huggett-type general equilibrium model with the CARAGaussian specification. Specifically, we explored how RI reduces general equilibrium interest rates via increasing individual precautionary savings and compared the general equilibrium results with the partial equilibrium results. The key implication of the model is that the general equilibrium effect reduces the welfare cost of imperfect information substantially; given that those costs are already estimated to be small, our work shows that it may easily be optimal for households to operate under substantial uncertainty even if the costs of information are negligible. ${ }^{31}$

\footnotetext{
${ }^{31}$ In Appendix 7.5 we extend our model to include durables as in Luo, Nie, and Young (2014). None of our results change.
} 


\section{Appendix}

\subsection{Deriving the Consumption and Saving Functions in the Huggett-type Model with RI}

Given the consumption function (4), the original budget constraint (2) can be rewritten as

$$
\begin{aligned}
& a_{t+1}+\phi y_{t+1}+\frac{\phi \phi_{0}}{r}=(1+r) a_{t}+y_{t}-c_{t}+\phi\left(\phi_{0}+\phi_{1} y_{t}+w_{t+1}\right)+\frac{\phi \phi_{0}}{r} \\
& =(1+r)\left(a_{t}+\phi y_{t}+\frac{\phi \phi_{0}}{r}\right)-c_{t}+\zeta_{t+1}
\end{aligned}
$$

where the $(t+1)$-innovation $\zeta_{t+1}=\phi w_{t+1}$ is Gaussian innovation process with mean zero and variance $\phi^{2} \sigma^{2}$. Denote $s_{t}=a_{t}+\phi y_{t}+\phi \phi_{0} / r$, the new budget constraint and the consumption function can be rewritten as

$$
\begin{aligned}
s_{t+1} & =(1+r) s_{t}-c_{t}+\zeta_{t+1}, \\
c_{t} & =r\left\{s_{t}+\frac{1}{r^{2} \alpha}\left[\ln \left(\frac{1+\rho}{1+r}\right)-\ln E_{t}\left[\exp \left(-r \alpha \phi w_{t+1}\right)\right]\right]\right\} .
\end{aligned}
$$

Under RI, the first-order condition with respective to $c$ and the Envelope Theorem give us

$$
\begin{aligned}
u^{\prime}\left(c_{t}\right) & =\frac{1}{1+\rho} E_{t}\left[\widehat{v}^{\prime}\left(\widehat{s}_{t+1}\right)\right], \\
\widehat{v}^{\prime}\left(\widehat{s}_{t}\right) & =\frac{1+r}{1+\rho} E_{t}\left[\widehat{v}^{\prime}\left(\widehat{s}_{t+1}\right)\right],
\end{aligned}
$$

which imply that

$$
u^{\prime}\left(c_{t}\right)=\frac{1}{1+r} \widehat{v}^{\prime}\left(\widehat{s}_{t}\right)
$$

Conjecture that the value function takes the form

$$
\widehat{v}\left(\widehat{s}_{t}\right)=-\frac{1}{r \alpha} \exp \left[-r \alpha\left(\widehat{s}_{t}+b\right)\right]
$$

Combining the exponential utility, (49) and (50), the candidate optimal consumption is given by

$$
c_{t}^{*}=r\left[\widehat{s}_{t}+b+\frac{1}{r \alpha} \ln (1+r)\right] .
$$


Plugging (51) into the utility function gives

$$
u\left(c_{t}^{*}\right)=-\frac{1}{\alpha} \exp \left(-\alpha c_{t}^{*}\right)=-\frac{1}{\alpha} \exp \left(-\alpha r\left[\widehat{s}_{t}+b+\frac{1}{r \alpha} \ln (1+r)\right]\right)=\frac{1}{1+r} \widehat{v}\left(\widehat{s}_{t}\right) .
$$

Substituting (52) into the Bellman Equation (50) leads to

$$
\widehat{v}\left(\widehat{s}_{t}\right)=\frac{1+r}{1+\rho} E_{t}\left[\widehat{v}\left(\widehat{s}_{t+1}\right)\right]
$$

Using (50) and (12), (53) implies that

$$
c_{t}^{*}=r\left\{\widehat{s}_{t}+\frac{1}{r^{2} \alpha}\left[\ln \left(\frac{1+\rho}{1+r}\right)-\ln \left(E_{t}\left[\exp \left(-r \alpha \widehat{\zeta}_{t+1}\right)\right]\right)\right]\right\} .
$$

Matching coefficients in (51) and (18) gives

$$
b=-\frac{1}{r \alpha} \ln (1+r)+\frac{1}{r^{2} \alpha}\left\{\ln \left(\frac{1+\rho}{1+r}\right)-\ln \left(E_{t}\left[\exp \left(-r \alpha \widehat{\zeta}_{t+1}\right)\right]\right)\right\} .
$$

By utilizing (4), (13) and (18), we can derive the savings function as follows:

$$
\begin{aligned}
d_{t}^{*} & =r a_{t}+y_{t}-c_{t}^{*} \\
& =r a_{t}+y_{t}-c_{t}+\left(c_{t}-c_{t}^{*}\right) \\
& =r a_{t}+y_{t}-r\left[a_{t}+\phi y_{t}+\frac{\phi \phi_{0}}{r}+\frac{1}{r^{2} \alpha}\left(\ln \left(\frac{1+\rho}{1+r}\right)-\ln \left(E_{t}\left[\exp \left(-r \alpha \phi w_{t+1}\right)\right]\right)\right)\right]+ \\
& \left\{\begin{array}{c}
r\left[a_{t}+\phi y_{t}+\phi \frac{\phi_{0}}{r}+\frac{1}{r^{2} \alpha}\left(\ln \left(\frac{1+\rho}{1+r}\right)-\ln \left(E_{t}\left[\exp \left(-r \alpha \phi w_{t+1}\right)\right]\right)\right)\right] \\
-r\left[\widehat{s}_{t}+\frac{1}{r^{2} \alpha}\left(\ln \left(\frac{1+\rho}{1+r}\right)-\ln \left(E_{t}\left[\exp \left(-r \alpha \widehat{\zeta}_{t+1}\right)\right]\right)\right)\right]
\end{array}\right\} \\
& =\left(1-\phi_{1}\right) \phi\left(y_{t}-\bar{y}\right)+r\left(s_{t}-\widehat{s}_{t}\right)+\frac{1}{r \alpha}\left[\ln \left(E_{t}\left[\exp \left(-r \alpha \widehat{\zeta}_{t+1}\right)\right]\right)-\ln \left(\frac{1+\rho}{1+r}\right)\right] .
\end{aligned}
$$

\subsection{Solving the Habit Formation Model}

As in Alessie and Lusardi (1997), we model habit formation in the Caballero model by assuming that the period utility is defined on $c_{t}-\gamma c_{t-1}$. The optimization problem for this habit formation model can be specified as follows:

$$
\max _{\left\{c_{t}\right\}} U(c)=E_{0}\left\{\sum_{t=0}^{\infty}\left(\frac{1}{1+\rho}\right)^{t}\left[-\frac{1}{\alpha} \exp \left(-\alpha\left(c_{t}-\gamma c_{t-1}\right)\right)\right]\right\}
$$


subject to the budget constraint

$$
s_{t+1}=(1+r) s_{t}-c_{t}+\zeta_{t+1}
$$

where $s_{t} \equiv a_{t}+\phi\left(y_{t}+\frac{\phi_{0}}{r}\right)$ and $\zeta_{t+1} \equiv \phi w_{t+1}=w_{t+1} /\left(1+r-\phi_{1}\right)$, and $\gamma>0$. The Bellman equation for this problem can be written as:

$$
v\left(s_{t}, c_{t-1}\right)=\max _{c_{t}}\left\{-\frac{1}{\alpha} \exp \left(-\alpha\left(c_{t}-\gamma c_{t-1}\right)\right)+\frac{1}{1+\rho} E_{t}\left[v\left(s_{t+1}, c_{t}\right)\right]\right\}
$$

where $v(s, c)$ is the value function.

To solve this Bellman equation, we first conjecture that: $v\left(s_{t}, c_{t-1}\right)=-\exp \left(-a_{0}\left(s_{t}+a_{1} c_{t-1}+a_{2}\right)\right) / a_{0}$, where $a_{0}, a_{1}$, and $a_{2}$ are undetermined coefficients. The FOC w.r.t. $c_{t}$ is

$$
\exp \left(-\alpha\left(c_{t}-\gamma c_{t-1}\right)\right)=\frac{1-a_{1}}{1+\rho} E_{t}\left[\exp \left(-a_{0}\left(s_{t+1}+a_{1} c_{t}+a_{2}\right)\right)\right]
$$

The Envelope theorem are:

$$
\begin{aligned}
\exp \left(-a_{0}\left(s_{t}+a_{1} c_{t-1}+a_{2}\right)\right) & =\frac{1+r}{1+\rho} E_{t}\left[\exp \left(-a_{0}\left(s_{t+1}+a_{1} c_{t}+a_{2}\right)\right)\right], \\
-\frac{a_{1}}{\gamma} \exp \left(-a_{0}\left(s_{t}+a_{1} c_{t-1}+a_{2}\right)\right) & =\exp \left(-\alpha\left(c_{t}-\gamma c_{t-1}\right)\right) .
\end{aligned}
$$

Combining (57) and (58) yields

$$
c_{t}=\frac{a_{0}}{\alpha} s_{t}+\left(\frac{a_{0} a_{1}}{\alpha}+\gamma\right) c_{t-1}-\frac{1}{\alpha}\left(\ln \left(\frac{1-a_{1}}{1+r}\right)-a_{0} a_{2}\right)
$$

Combining (57) and (59) yields

$$
c_{t}=\frac{1}{a_{0}\left(1-a_{1}\right)}\left[a_{0} r s_{t}-a_{0} a_{1} c_{t-1}+\ln \left(-\frac{a_{1}(1+\rho)}{\gamma\left(1-a_{1}\right)}\right)-\ln \left(E_{t}\left(\exp \left(-a_{0} \zeta_{t+1}\right)\right)\right)\right] .
$$

Comparing the two consumption functions, (60) and (61), we can determine the coefficients in the 
conjectured value function:

$$
\begin{aligned}
& a_{0}=\frac{\alpha r(1+r-\gamma)}{1+r} \\
& a_{1}=-\frac{\gamma}{1+r-\gamma^{\prime}} \\
& a_{2}=\frac{1+r}{r(1+r-\gamma)}\left\{\frac{1}{\alpha} \ln \left(\frac{1}{1+r-\gamma}\right)+\frac{1}{\alpha r}\left[\ln \left(\frac{1+\rho}{1+r}\right)-\ln \left(E_{t}\left[\exp \left(-\frac{\alpha r(1+r-\gamma)}{1+r} \zeta_{t+1}\right)\right]\right)\right]\right\} .
\end{aligned}
$$

Substituting these coefficients into (60) yields the consumption function in the main text.

Substituting the state transition equation into the consumption function yields:

$$
c_{t}-r s_{t}=\gamma\left(c_{t-1}-r s_{t-1}\right)-\frac{r \gamma}{r+1} \zeta_{t}+\frac{1}{r \alpha}\left(\ln \left(\frac{1+\rho}{1+r}\right)-\ln \left(E_{t}\left[\exp \left(-\frac{\alpha r(1+r-\gamma)}{1+r} \zeta_{t+1}\right)\right]\right)\right) .
$$

Combining (62) with $d_{t} \equiv r a_{t}+y_{t}-c_{t}$, we can rewrite the individual saving function as follows:

$$
\begin{aligned}
d_{t} & =r a_{t}+y_{t}-c_{t} \\
& =\left(1-r /\left(1+r-\phi_{1}\right)\right) y_{t}+\left(1-\phi_{1}\right) \bar{y} /\left(1+r-\phi_{1}\right)-r\left[\begin{array}{c}
-\frac{r \gamma}{r+1} \frac{\zeta_{t}}{1-\gamma \cdot L} \\
+\frac{1}{r \alpha(1-\gamma)}\left(\ln \left(\frac{1+\rho}{1+r}\right)-\ln \left(E _ { t } \left[\exp \left(-\frac{\alpha r(1+r-\gamma)}{1+r} \zeta_{t+1}\right)\right.\right.\right. \\
\end{array}=\left(1-\phi_{1}\right) \phi\left(y_{t}-\bar{y}\right)+\frac{r^{2} \gamma}{r+1} \frac{\zeta_{t}}{1-\gamma \cdot L}-\frac{1}{\alpha(1-\gamma)}\left(\ln \left(\frac{1+\rho}{1+r}\right)-\ln \left(E_{t}\left[\exp \left(-\frac{r \alpha(1+r-\gamma)}{1+r} \zeta_{t+1}\right)\right]\right)\right)\right.
\end{aligned}
$$

where we use the facts that $\phi_{0}=\left(1-\phi_{1}\right) \bar{y}$ and $\phi=1 /\left(1+r-\phi_{1}\right)$.

\subsection{Computing the Welfare Loss due to RI}

Given that the value function under RI in general equilibrium is

$$
\widehat{v}\left(\widehat{s}_{0}\right)=-\frac{1}{r^{*} \alpha} \exp \left(-r^{*} \alpha \widehat{s}_{0}+\ln \left(1+r^{*}\right)\right)
$$

we can compute the following partial derivatives:

$$
\frac{\partial \widehat{v}\left(\widehat{s}_{0}\right)}{\partial \theta}=\frac{\exp \left(-r^{*} \alpha \widehat{s}_{0}\right)}{r^{* 2} \alpha}\left[1+r^{*} \alpha \widehat{s}_{0}\left(1+r^{*}\right)\right] \frac{d r^{*}}{d \theta} \text { and } \frac{\partial \widehat{v}\left(\widehat{s}_{0}\right)}{\partial \widehat{s}_{0}}=\left(1+r^{*}\right) \exp \left(-r^{*} \alpha \widehat{s}_{0}\right)
$$

The marginal welfare cost due to RI can thus be written as:

$$
m w c \equiv \frac{\left(\partial v\left(\widehat{s}_{0}\right) / \partial \theta\right) \theta}{\left(\partial v\left(\widehat{s}_{0}\right) / \partial \widehat{s}_{0}\right) \widehat{s}_{0}}=\frac{\theta}{r^{* 2} \alpha}\left[r^{*} \alpha+\frac{1}{\left(1+r^{*}\right) \widehat{s}_{0}}\right] \frac{d r^{*}}{d \theta}
$$


where we use the facts that in general equilibrium (i.e., $\ln \left(\frac{1+\rho}{1+r}\right)=\ln \left(E_{t}\left[\exp \left(-r^{*} \alpha \widehat{\zeta}_{t+1}\right)\right]\right)$ ), and $d r^{*} / d \theta$ is given in (29).

\subsection{Solving the RU Model}

Guess that $\widehat{v}\left(\widehat{s}_{t}\right)=A \widehat{s}_{t}+A_{0}$, where $A$ and $A_{0}$ are undetermined coefficients. The Bellman equation becomes

$$
\widehat{v}\left(\widehat{s}_{t}\right)^{\frac{\eta-1}{\eta}}=\max _{c_{t}}\left\{(1-\beta) c_{t}^{\frac{\eta-1}{\eta}}+\beta\left[A\left(R \widehat{s}_{t}-c_{t}\right)+A_{0}-\frac{1}{\alpha} \ln \left(E_{t}\left[\exp \left(-\alpha A \widehat{\zeta}_{t+1}\right)\right]\right)\right]^{\frac{\eta-1}{\eta}}\right\} .
$$

The optimality gives

$$
\begin{aligned}
c_{t} & =(1-\beta)^{\eta}(\beta A)^{-\eta} Q, \\
\widehat{v}\left(\widehat{s}_{t}\right) & =(\beta(1+r))^{-\eta} Q,
\end{aligned}
$$

where $Q_{t} \equiv A\left((1+r) \widehat{s}_{t}-c_{t}\right)+A_{0}-\ln \left(E_{t}\left[\exp \left(-\alpha A \widehat{\zeta}_{t+1}\right)\right]\right) / \alpha$. Combining these two equations yields:

$$
\widehat{v}\left(\widehat{s}_{t}\right)=\left(\frac{A}{1+r}\right)^{\eta}(1-\beta)^{-\eta} c_{t}
$$

and

$$
(\beta(1+r))^{\eta}\left(A \widehat{s}_{t}+A_{0}\right)=Q=A(1+r) \widehat{s}_{t}-\varphi\left(\frac{A}{1+r}\right)^{-\eta}(1-\beta)^{\eta}\left(A \widehat{s}_{t}+A_{0}\right)+A_{0}-\frac{1}{\alpha} \ln \left(E_{t}\left[\exp \left(-\alpha A \widehat{\zeta}_{t+1}\right)\right]\right.
$$

They can be reduced to

$$
\begin{aligned}
(\beta(1+r))^{\eta} A & =A(1+r)-A^{1-\eta}(1+r)^{\eta}(1-\beta)^{\eta} A \\
(\beta(1+r))^{\eta} A_{0} & =-A\left(\frac{A}{1+r}\right)^{-\eta}(1-\beta)^{\eta} A_{0}+A_{0}-\frac{1}{\alpha} \ln \left(E_{t}\left[\exp \left(-\alpha A \widehat{\zeta}_{t+1}\right)\right]\right),
\end{aligned}
$$

which implies that

$$
A=(1+r-\delta)^{\frac{1}{1-\eta}}\left(1+r-\delta^{\frac{1}{\eta}}\right)^{\frac{\eta}{\eta-1}} \text { and } A_{0}=-\frac{1}{r \alpha} \ln \left(E_{t}\left[\exp \left(-\alpha A \widehat{\zeta}_{t+1}\right)\right]\right) .
$$

Substituting these two coefficients into the guessed value function yields the value function under RI in the text. Furthermore, substituting $\widehat{v}\left(\widehat{s}_{t}\right)$ into $c_{t}=\left(\frac{A}{1+r}\right)^{-\eta}(1-\beta)^{\eta} \widehat{v}\left(\widehat{s}_{t}\right)$ yields the consumption function under RI in the text. Finally, the consumption function can be decomposed 
as follows:

$$
\begin{aligned}
c_{t}^{*} & =(1+r-\delta)\left\{\widehat{s}_{t}-\frac{1}{r \alpha A} \ln \left(E_{t}\left[\exp \left(-\alpha A\left[\theta(1+r)\left(s_{t}-\widehat{s}_{t}\right)+\theta\left(\zeta_{t+1}+\xi_{t+1}\right)\right]\right)\right]\right)\right\} \\
& =(1+r-\delta)\left\{\widehat{s}_{t}-\frac{1}{r \alpha A}\left[\ln \left(E_{t}\left[\exp \left(-\alpha A \theta(1+r)\left(s_{t}-\widehat{s}_{t}\right)\right)\right]\right)+\ln \left(E_{t}\left[\exp \left(-\alpha A \theta \tau_{t+1}\right)\right]\right)+\ln E_{t}[\exp (-\alpha A \theta \xi\right.\right. \\
& =(1+r-\delta)\left\{\widehat{s}_{t}-\frac{1}{r \alpha A}\left[\frac{(\alpha A \theta a \sigma)^{2}}{2 \theta\left[1-(1-\theta)(1+r)^{2}\right]}+\frac{(\alpha A a \sigma)^{2}}{2}+\frac{(1-\theta)(\alpha A \theta a \sigma)^{2}}{2 \theta\left[1-(1-\theta)(1+r)^{2}\right]}\right]\right\} \\
& =(1+r-\delta)\left[\widehat{s}_{t}-\frac{(\alpha A \theta a \sigma)^{2}}{2 \alpha A \theta r\left(1-(1-\theta)(1+r)^{2}\right)}\right]
\end{aligned}
$$

Substituting the consumption function into the saving function, we have

$$
\begin{aligned}
d_{t} & =r a_{t}+y_{t}-c_{t} \\
& =r a_{t}+y_{t}-(1+r-\delta)\left(\widehat{s}_{t}-\frac{1}{r} \varepsilon^{*}\right) \\
& =r a_{t}+y_{t}-r s_{t}-(1-\delta) s_{t}+\frac{1+r-\delta}{r} \varepsilon^{*}-(1+r-\delta)\left(\widehat{s}_{t}-s_{t}\right) \\
& =r a_{t}+y_{t}-r\left(a_{t}+\phi y_{t}+\frac{\phi \phi_{0}}{r}\right)-(1-\delta)\left(s_{t}-\bar{s}\right)-(1-\delta) \bar{s}+\frac{1+r-\delta}{r} \varepsilon^{*}-(1+r-\delta)\left(\widehat{s}_{t}-s_{t}\right) \\
& =f_{t}-(1-\delta)\left(s_{t}-\bar{s}\right)-(1-\delta) \bar{s}+\frac{1+r-\delta}{r} \varepsilon^{*}-(1+r-\delta)\left(\widehat{s}_{t}-s_{t}\right),
\end{aligned}
$$

where we use the facts that $s_{t}=a_{t}+\phi\left(y_{t}+\phi_{0} / r\right), \phi_{0}=\left(1-\phi_{1}\right) \bar{y}, \phi=1 /\left(1+r-\phi_{1}\right)$, and $f_{t}=\left(1-\phi_{1}\right) \phi\left(y_{t}-\bar{y}\right)$.

\subsection{An Extension to Incorporate Durable Consumption}

Following Bernanke (1985) and Gali (1993), we consider an FI-RE version of the PIH model which includes both durable and nondurable consumption. The optimizing decisions of a representative consumer in the RE-PIH model with durables goods can be formulated as

$$
\max _{\left\{c_{t}, k_{t+1}\right\}_{t=0}^{\infty}}\left\{E_{0}\left[\sum_{t=0}^{\infty} \beta^{t} u\left(c_{t}, k_{t}\right)\right]\right\},
$$

subject to the budget constraint

$$
a_{t+1}=(1+r) a_{t}+y_{t}-c_{t}-e_{t}
$$


and the accumulation equation for durables

$$
k_{t+1}=(1-\delta) k_{t}+e_{t},
$$

where $u\left(c_{t}, k_{t}\right)=-\exp \left(-\alpha_{c} c_{t}\right) / \alpha_{c}-\varrho \exp \left(-\alpha_{k} k_{t}\right) / \alpha_{k}$ is the utility function, $c_{t}$ is consumption of nondurables, $k_{t}$ is the stock of durables goods, $e_{t}$ is the purchase of durable goods, $\beta=1 /(1+\rho)$ is the discount factor, $R=1+r$ is the constant gross interest rate, $\delta$ is the depreciation rate of durable goods, $\alpha_{c}>0, \alpha_{k}>0$, and $\varrho>0$.

To incorporate RI, following the same procedure used in the our benchmark model and Luo, Nie, and Young (2014), we define a new state variable (s) as:

$$
s_{t} \equiv a_{t}+\frac{1-\delta}{1+r} k_{t}+\frac{1}{1+r-\phi_{1}}\left(\frac{\phi_{0}}{r}+y_{t}\right)
$$

which is governed by the following evolution equation:

$$
s_{t+1}=(1+r) s_{t}-c_{t}-\frac{r+\delta}{(1+r)} k_{t+1}+\zeta_{t+1}
$$

where $\zeta_{t+1}=\phi w_{t+1}=\frac{1}{1+r-\phi_{1}} w_{t+1}$ is the innovation to $s_{t+1}$.

Following Luo, Nie, and Young (2014), we formulate the optimization problem for the typical household under RI:

$$
v\left(\widehat{s}_{t}\right)=\max _{\left\{c_{t}, k_{t+1}\right\}}\left\{E_{t}\left[u\left(c_{t}, k_{t}\right)+\beta v\left(\widehat{s}_{t+1}\right)\right]\right\}
$$

subject to

$$
\widehat{s}_{t+1}=(1+r) \widehat{s}_{t}-c_{t}-\frac{r+\delta}{1+r} k_{t+1}+\widehat{\zeta}_{t+1}
$$

where $\widehat{\zeta}_{t+1}$ is defined in (14) and $\widehat{s}_{0}$ is given, The following proposition summarizes the results from the above dynamic program:

Proposition 9. Under RI, the functions of nondurable consumption and the stock of durable accumulation are:

$$
\begin{aligned}
c_{t} & =H_{c} \widehat{s}_{t}+\Omega_{c}+\widehat{\Pi}_{c}, \\
k_{t+1} & =\Omega+\frac{\alpha_{c}}{\alpha_{k}} c_{t},
\end{aligned}
$$

respectively, where $H_{c}=r\left(1+\frac{r+\delta}{1+r} \frac{\alpha_{c}}{\alpha_{k}}\right)^{-1}, \Omega=-\frac{1}{\alpha_{k}} \ln \left(\frac{r+\delta}{\varrho}\right), \Omega_{c}=-\left(1-\frac{1-\delta}{1+r}\right)\left(1+\frac{r+\delta}{1+r} \frac{\alpha_{c}}{\alpha_{k}}\right)^{-1} \Omega$, 
$\widehat{\Pi}_{c}=-\widehat{\Pi} / r$, and

$$
\widehat{\Pi} \equiv \frac{1}{\alpha_{c}} \ln (\beta(1+r))+\frac{\alpha_{c}}{2}\left(\frac{r}{1+r-\phi_{1}}\right)^{2}\left(1+\frac{r+\delta}{1+r} \frac{\alpha_{c}}{\alpha_{k}}\right)^{-2} \Gamma(r, \theta) \phi^{2} \sigma^{2}
$$

Proof. See Online Appendix.

Given the original budget constraint and the decision rules, the expression for individual saving, $d_{t} \equiv r a_{t}+y_{t}-c_{t}-\left[k_{t+1}-(1-\delta) k_{t}\right]$, can be written as:

$$
\begin{aligned}
d_{t} & =\frac{r}{1+r-\phi_{1}}\left[1-\left(1+\frac{\alpha_{c}}{\alpha_{k}}\right)\left(1+\frac{r+\delta}{1+r} \frac{\alpha_{c}}{\alpha_{k}}\right)^{-1}\right] \widehat{\zeta}_{t}+r\left(s_{t}-\widehat{s}_{t}\right) \\
& +\left[\frac{1+r}{H_{c}}-\left(1+\frac{\alpha_{c}}{\alpha_{k}}\right)\right] \widehat{\Pi}+\frac{r}{1+r-\phi_{1}}\left(y_{t}-\bar{y}\right),
\end{aligned}
$$

where $s_{t}-\widehat{s}_{t}$ is defined in (15), respectively.

After aggregating across all consumers using the same law of large number we applied in the benchmark model, all the idiosyncratic shocks (including the fundamental income shocks and endogenous shocks due to RI) are canceled out and we obtain the following expression for aggregate saving:

$$
D(\theta, r) \equiv\left[\frac{1+r}{H_{c}}-\left(1+\frac{\alpha_{c}}{\alpha_{k}}\right)\right] \widehat{\Pi}
$$

where $\widehat{\Pi}$ is defined in (70). The following proposition proves the existence of a general equilibrium and shows the PIH holds in such an equilibrium.

Proposition 10. There exists at least one equilibrium with an interest rate $r^{*} \in(0, \rho)$ in the RI precautionarysavings model with durables. In any such equilibrium, the aggregate saving is zero:

$$
\frac{1}{2}\left(\alpha_{c} r^{*}\right)^{2}\left(1+\frac{\delta+r^{*}}{1+r^{*}} \frac{\alpha_{c}}{\alpha_{k}}\right)^{-2} \Gamma\left(r^{*}, \theta\right) \omega_{\zeta}^{2}-\ln \left(\frac{1+\rho}{1+r^{*}}\right)=0
$$

The PIH holds since consumption follows

$$
c_{t}=H_{c} \widehat{s}_{t}+\Omega_{c} .
$$

Proof. The proof is the same as that in the benchmark model. Here we need to assume that $\frac{1+r^{*}}{H_{c}}-$ $\left(1+\frac{\alpha_{c}}{\alpha_{k}}\right) \neq 0$.

We now examine how rational inattention affects the equilibrium interest rate in the CARA- 
Gaussian setting with durable consumption. Luo, Nie and Young (2014) show that if $\frac{\alpha_{c}}{\alpha_{k}}=\frac{r+\delta}{\varrho}$ holds, then the model here is observational equivalent to the LQ Gaussian model with durables. Using the estimated parameters in Bernanke (1985) $(\delta=0.025$, and $\varrho=0.0286)$ and $\alpha_{c}=2$ used in Caballero (1991) and Wang (2000), we calibrate the CARA parameter on durable consumption: $\alpha_{k}=1.63$. Given the following parameter values: $\alpha_{c}=2, \alpha_{k}=1.63, \sigma=0.29, \phi_{1}=0.88, \rho=0.04$, $\delta=0.025$, and $\varrho=0.0286$, Figure ?? illustrates how $r^{*}$ varies with the value of $\theta$. The figure also clearly shows that the aggregate saving function is increasing with the interest rate and the general equilibrium interest rate is decreasing with the degree of inattention, which is consistent with the conclusion obtained in our benchmark model without durable goods.

\section{References}

[1] Alessie, Rob and Annamaria Lusardi (1997), "Consumption, Saving and Habit Formation," Economics Letters 55(1), 103-108.

[2] Attanasio, Orazio P. and Nicola Pavoni (2011), "Risk Sharing in Private Information Models with Asset Accumulation: Explaining the Excess Smoothness of Consumption," Econometrica 79(4), 1027-1068.

[3] Athreya, Kartik, Xuan S. Tam, and Eric R. Young (2009), "Unsecured Credit Markets Are Not Insurance Markets," Journal of Monetary Economics 56(1), 83-103.

[4] Aiyagari, Rao S. (1994), “Uninsured Idiosyncratic Risk and Aggregate Saving," Quarterly Journal of Economics 109 (3), 658-684.

[5] Barro, Robert J. (2007), “On the Welfare Costs of Consumption Uncertainty," manuscript.

[6] Bernanke, Ben (1985), “Adjustment Costs, Durables, and Aggregate Consumption," Journal of Monetary Economics 15, 41-68.

[7] Blundell Richard, Luigi Pistaferri, and Ian Preston (2008), “Consumption Inequality and Partial Insurance," American Economic Review 98(5), 1887-1921.

[8] Caballero, Ricardo J. (1990), “Consumption Puzzles and Precautionary Savings,” Journal of Monetary Economics 25, 113-136.

[9] Caballero, Ricardo J. (1991), “Earnings Uncertainty and Aggregate Wealth Accumulation," American Economic Review 81(4), 859-871.

[10] Campbell, John Y. and Angus S. Deaton (1989), “Why Is Consumption So Smooth?” Review of Economic Studies 56(3), 357-373. 
[11] Dynan, Karen E. (2000), “Habit Formation in Consumer Preferences: Evidence from Panel Data," American Economic Review 90(3), 391-406.

[12] Floden, Martin and Jesper Lindé (2001), "Idiosyncratic Risk in the United States and Sweden: Is There a Role for Government Insurance?" Review of Economic Dynamics 4, 406-437.

[13] Friedman, Milton (1957), "A Theory of the Consumption Function," Princeton, NJ: Princeton University Press.

[14] Galí, Jordi (1993), “Variability of Durable and Nondurable Consumption: Evidence for Six O.E.C.D. Countries," Review of Economics and Statistics 75, 418-428.

[15] Guvenen, Fatih and Anthony A. Smith, Jr., (2014), "Inferring Labor Income Risk and Partial Insurance from Economic Choices," forthcoming Econometrica.

[16] Hall, Robert E. (1978), "Stochastic Implications of the Life Cycle-Permanent Income Hypothesis: Theory and Evidence," Journal of Political Economy 91(6), 249-265.

[17] Huggett, Mark (1993), “The Risk-Free Rate in Heterogeneous-Agent Incomplete-Insurance Economies," Journal of Economic Dynamics and Control 17(5-6), 953-969.

[18] Kahneman, Daniel (1973), Attention and Effort, Prentice-Hall Press.

[19] Krueger Dirk and Fabrizio Perri (2006), “Does Income Inequality Lead to Consumption Inequality? Evidence and Theory," Review of Economic Studies 73(1), 163-193.

[20] Luo, Yulei (2008), “Consumption Dynamics under Information Processing Constraints," Review of Economic Dynamics 11, 366-385.

[21] Luo, Yulei (2010), “Rational Inattention, Long-Run Consumption Risk, and Portfolio Choice," Review of Economic Dynamics 13(4), 843-860.

[22] Luo, Yulei and Eric R. Young (2010), “Risk-sensitive Consumption and Savings under Rational Inattention," American Economic Journal: Macroeconomics 2(4), 281-325.

[23] Luo, Yulei and Eric R. Young (2014), “Signal Extraction and Rational Inattention," Economic Inquiry 52(2), 811-829.

[24] Luo, Yulei, Jun Nie, and Eric R. Young. (2014), "Slow Information Diffusion and the Inertial Behavior of Durable Consumption," forthcoming, Journal of the European Economic Association.

[25] Maćkowiak, Bartosz and Mirko Wiederholt (2013), "Business Cycle Dynamics under Rational Inattention," manuscript. 
[26] Mondria, Jordi (2010), "Portfolio Choice, Attention Allocation, and Price Comovement," Journal of Economic Theory 145(5), 1837-1864.

[27] Peng, Lin (2004), "Learning with Information Capacity Constraints," Journal of Financial and Quantitative Analysis 40, 307-330.

[28] Pischke, Jorn-Steffen (1995), “Individual Income, Incomplete Information, and Aggregate Consumption," Econometrica 63, 805-840.

[29] Reis, Ricardo (2006), "Inattentive consumers," Journal of Monetary Economics 53(8), 1761-1800.

[30] Shafieepoorfard, Ehsan and Maxim Raginsky (2013), "Rational Inattention in Scalar LQG Control," Proceedings of the IEEE Conference on Decision and Control 52, 5733-5739.

[31] Sims, Christopher A. (2003), "Implications of Rational Inattention," Journal of Monetary Economics 50 (3), 665-690.

[32] Sims, Christopher A. (2010), "Rational Inattention and Monetary Economics," Handbook of Monetary Economics.

[33] Sun, Yeneng (2006), "The Exact Law of Large Numbers via Fubini Extension and Characterization of Insurable Risks," Journal of Economic Theory 126, 31-69.

[34] Wang, Susheng (2000), "Determinants of Aggregate Weath," Macroeconomic Dynamics 4(1), 2241.

[35] Wang, Neng (2003), “Caballero Meets Bewley: The Permanent-Income Hypothesis in General Equilibrium," American Economic Review 93(3), 927-936.

[36] Wang, Neng (2004), “Precautionary Saving and Partially Observed Income," Journal of Monetary Economics 51, 1645-1681.

[37] Wang, Neng (2006), "An Equilibrium Model of Wealth Distribution," Journal of Monetary Economics 54(7), 1882-1904.

[38] Van Nieuwerburgh, Stijn and Laura Veldkamp (2010), “Information Acquisition and UnderDiversification," Review of Economic Studies 77(2), 779-805. 


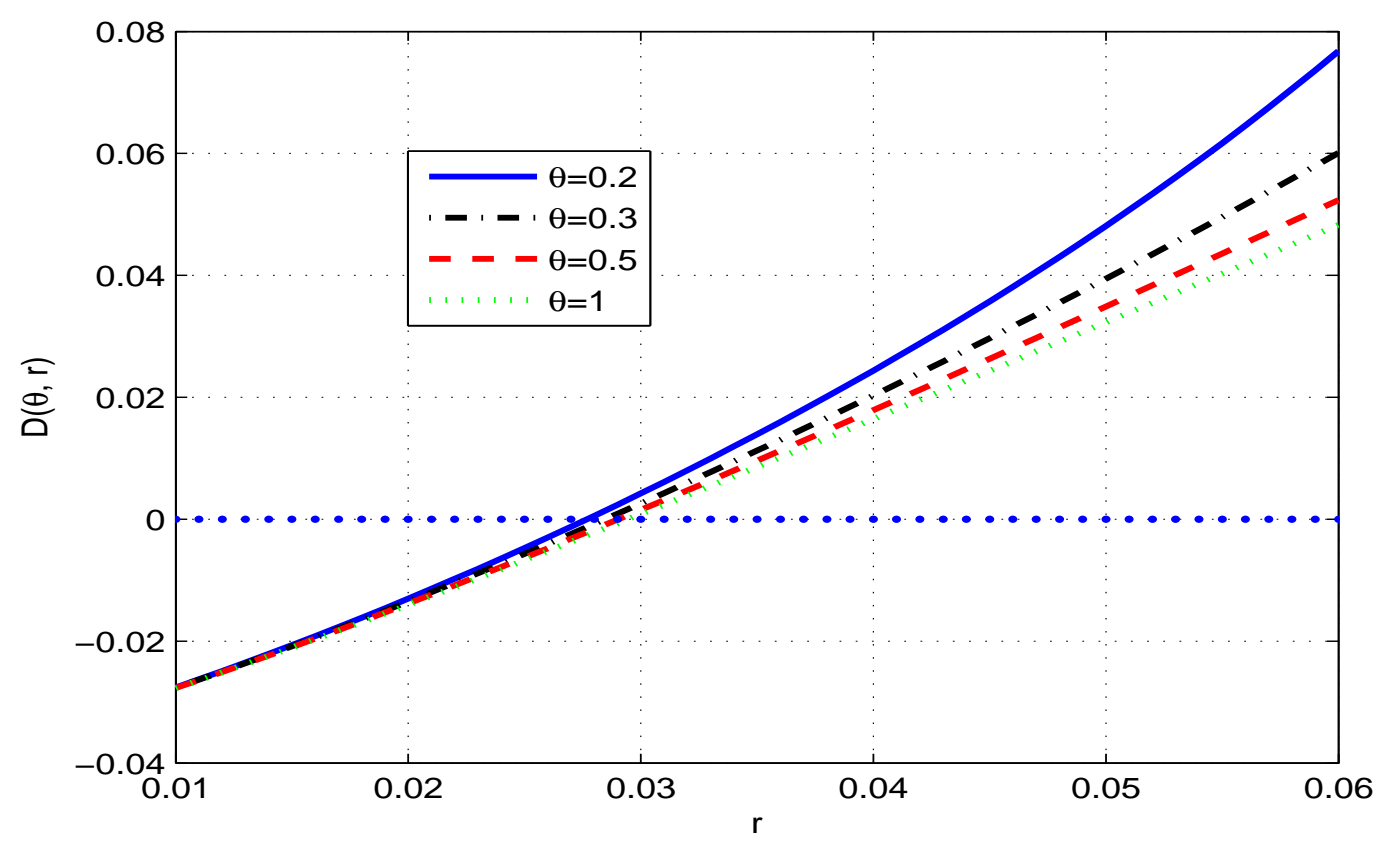

Figure 1. Effects of RI on Aggregate Saving 


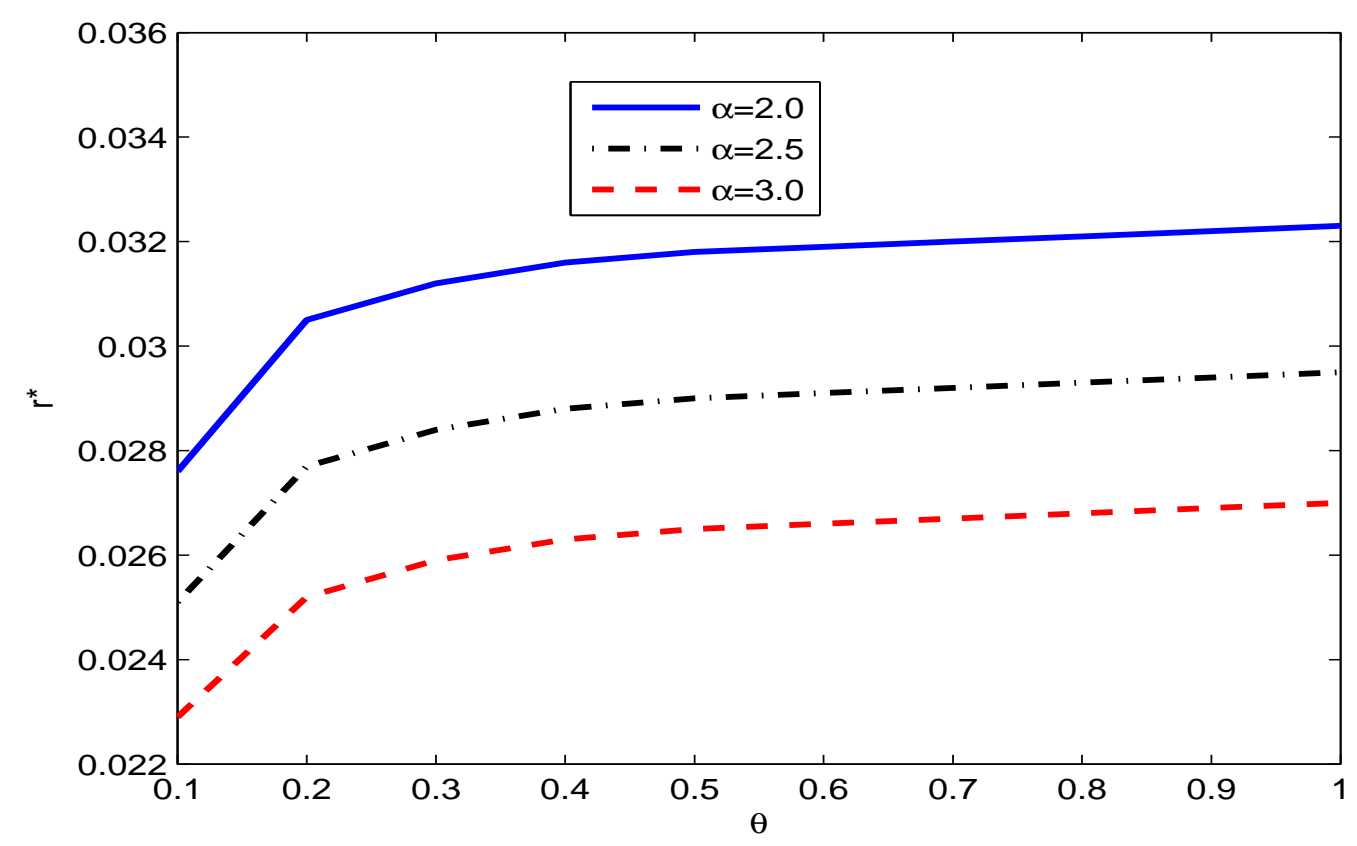

Figure 2. Effects of RI on the Equilibrium Interest Rate

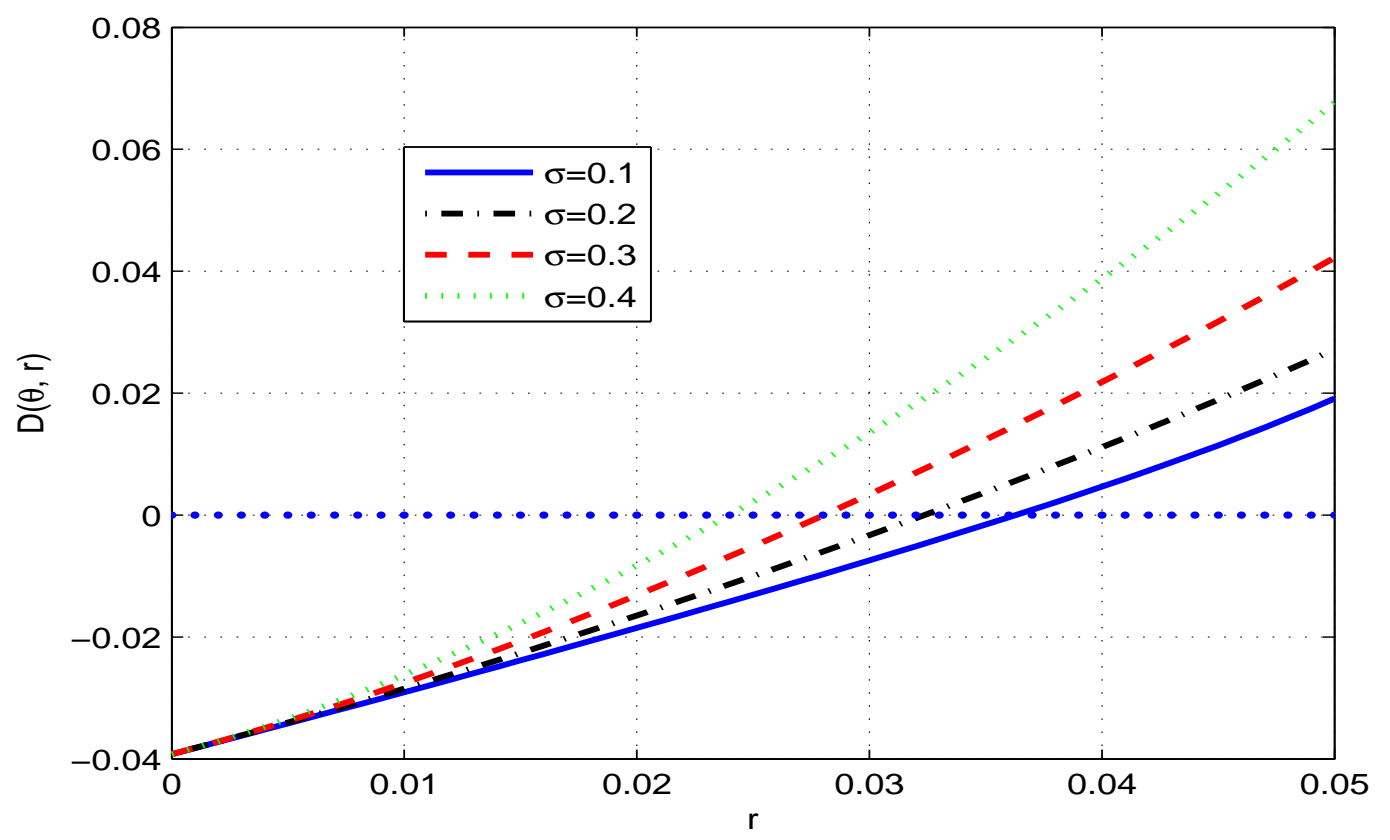

Figure 3. Effects of Income Volatility on the Interest Rate in GE (Elastic $\kappa$ ) 


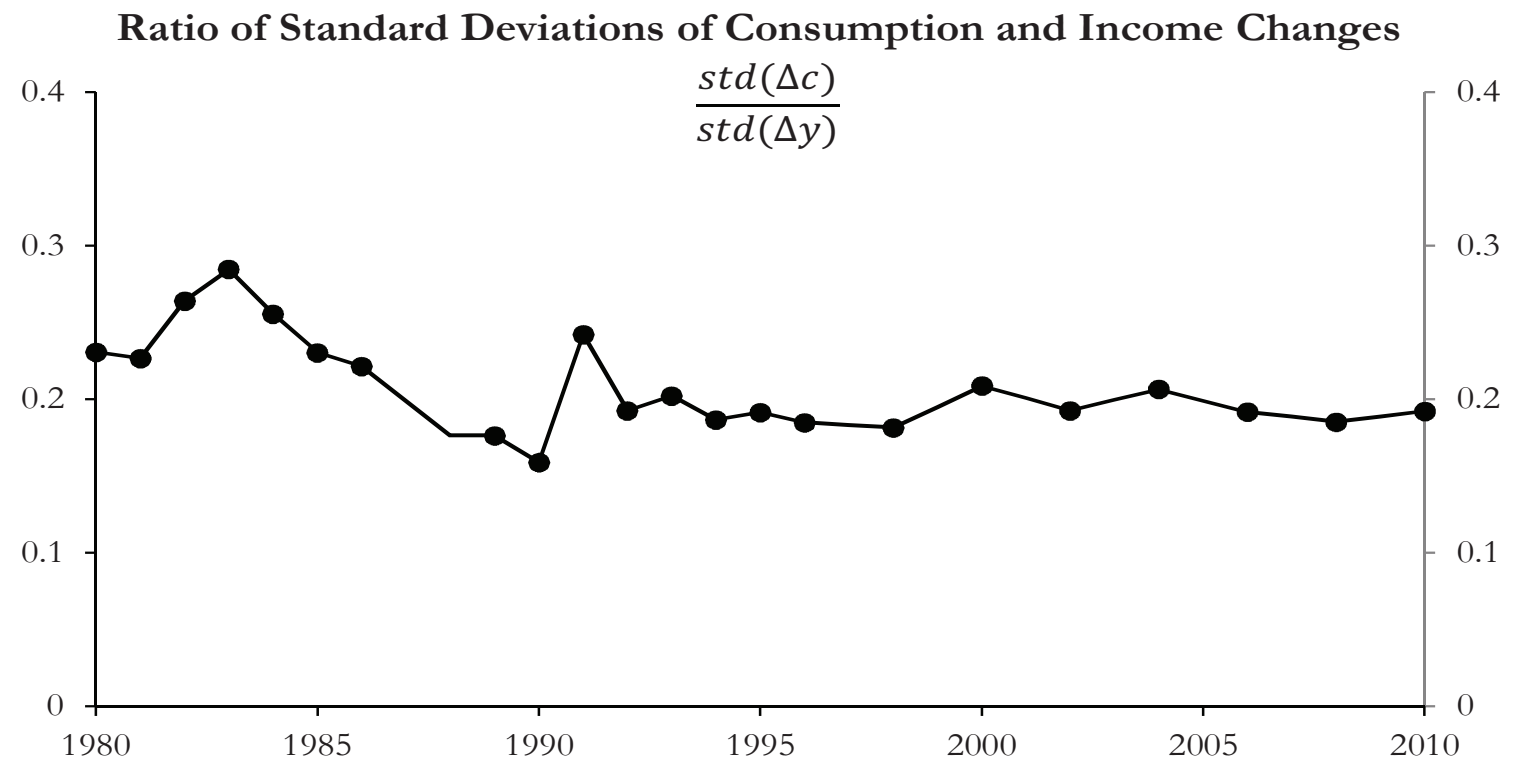

*Note: Values in 1987 and 1988 are excluded due to missing PSID consumption values.

Figure 4. Relative Consumption Dispersion

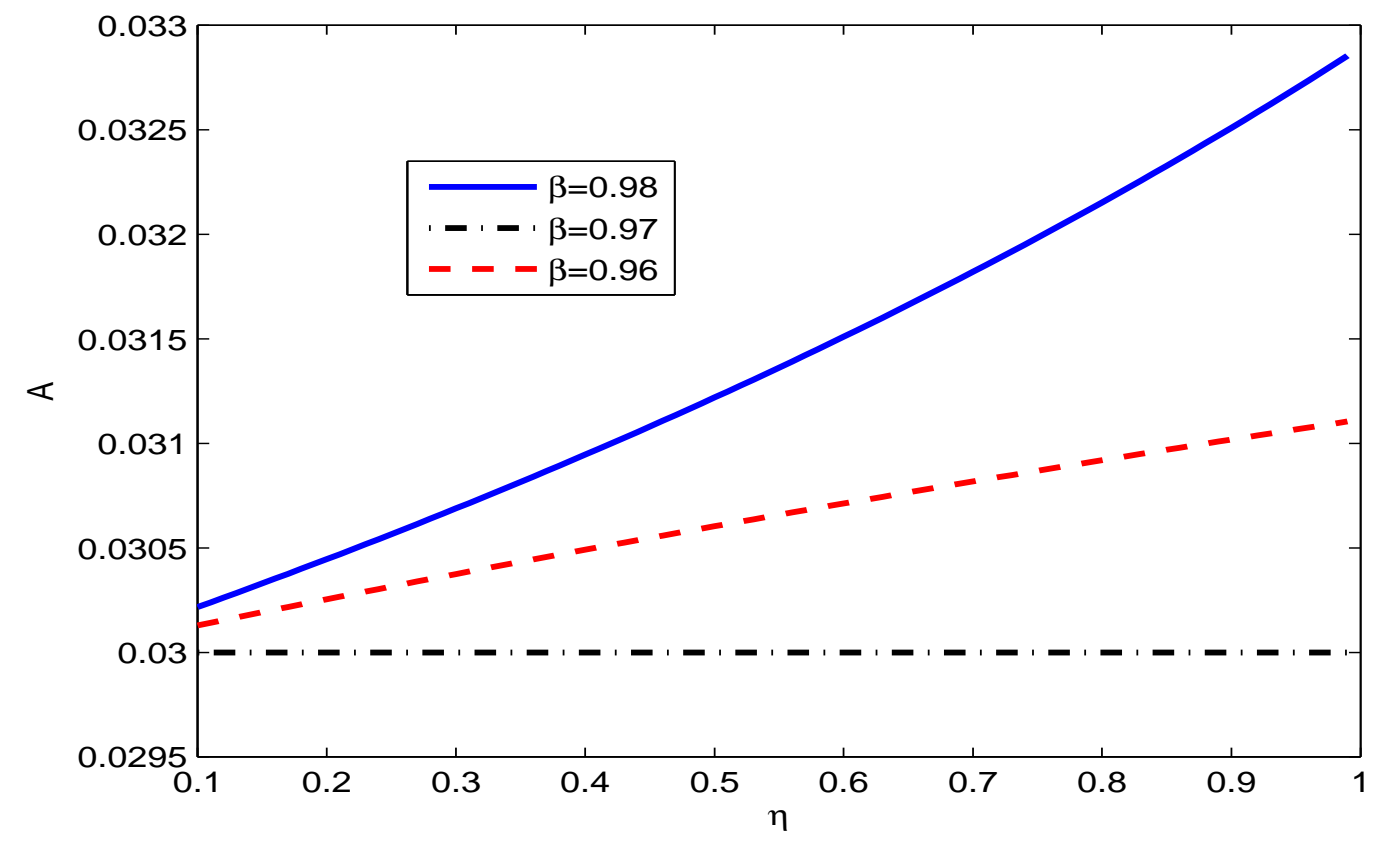

Figure 5. Effects of RI on the Equilibrium Interest Rate 


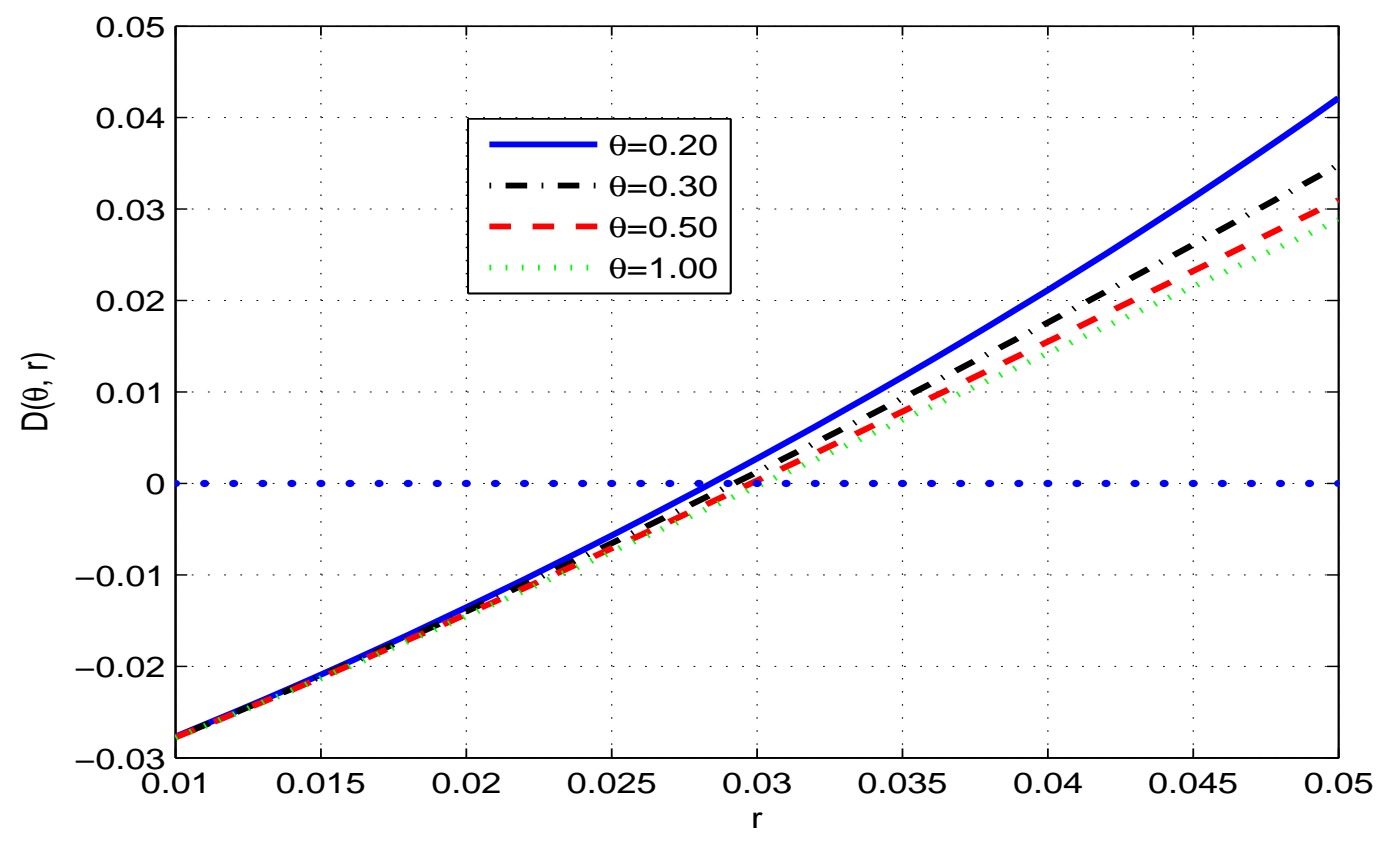

Figure 6. Effects of RI on the Equilibrium Interest Rate

Table 1. Implications of RI for interest rates, Consumption, and Welfare

\begin{tabular}{cccccccc}
\hline \hline & $\theta$ & 0.1 & 0.2 & 0.4 & 0.6 & 0.8 & 1 \\
\hline \multirow{2}{*}{ GE } & $r^{*}$ & $2.51 \%$ & $2.77 \%$ & $2.88 \%$ & $2.91 \%$ & $2.93 \%$ & $2.95 \%$ \\
& $\mu_{c y}$ & 0.227 & 0.206 & 0.196 & 0.193 & 0.192 & 0.191 \\
& $\mu_{a y}$ & 2.145 & 1.940 & 1.776 & 1.706 & 1.665 & 1.639 \\
& $\$$ loss $/ \widehat{y}_{0}$ & $1.316 \times 10^{-3}$ & $1.195 \times 10^{-3}$ & $9.040 \times 10^{-4}$ & $6.040 \times 10^{-4}$ & $3.025 \times 10^{-4}$ & 0 \\
\hline \multirow{2}{*}{$\mathrm{PE}$} & $\mu_{c y}$ & 0.282 & 0.219 & 0.201 & 0.195 & 0.193 & 0.191 \\
$(r=2.95 \%)$ & $\mu_{a y}$ & 2.202 & 1.935 & 1.771 & 1.702 & 1.663 & 1.639 \\
& $\$$ loss $/ \widehat{y}_{0}$ & $1.363 \times 10^{-3}$ & $1.212 \times 10^{-3}$ & $9.089 \times 10^{-4}$ & $6.059 \times 10^{-4}$ & $3.030 \times 10^{-4}$ & 0 \\
\hline
\end{tabular}


Table 2. Implications of RI in GE and PE (Elastic $\kappa$ )

\begin{tabular}{cccccc}
\hline \hline & $\sigma\left(\sigma_{y}\right)$ & $0.1(0.21)$ & $0.2(0.42)$ & $0.3(0.63)$ & $0.4(0.84)$ \\
\hline GE-RI $(\lambda=50)$ & $\theta$ & 0.100 & 0.177 & 0.251 & 0.322 \\
& $r^{*}$ & $3.528 \%$ & $3.184 \%$ & $2.771 \%$ & $2.402 \%$ \\
& $\mu_{c y}$ & 0.370 & 0.243 & 0.199 & 0.171 \\
& $\mu_{a y}$ & 2.318 & 1.973 & 1.880 & 1.846 \\
\hline GE-FI $(\theta=1)$ & $r^{*}$ & $3.811 \%$ & $3.375 \%$ & $2.899 \%$ & $2.483 \%$ \\
& $\mu_{c y}$ & 0.234 & 0.213 & 0.189 & 0.166 \\
& $\mu_{a y}$ & 1.549 & 1.593 & 1.644 & 1.691 \\
\hline PE $(r=2.771 \%, \lambda=50)$ & $\theta$ & 0.098 & 0.178 & 0.251 & 0.317 \\
& $\mu_{c y}$ & 0.262 & 0.211 & 0.199 & 0.194 \\
& $\mu_{a y}$ & 2.187 & 1.968 & 1.880 & 1.828 \\
\hline
\end{tabular}

Table 3. Estimation of the Income Process with Sub-samples

\begin{tabular}{cccc|cccc}
\hline Period 1 & std $\left(\epsilon_{i t}\right)$ & $\phi_{i t}$ & std $\left(y_{i t}\right)$ & Period 2 & std $\left(\epsilon_{i t}\right)$ & $\phi_{i t}$ & std $\left(y_{i t}\right)$ \\
\hline $1980-1986$ & 0.25 & 0.85 & 0.47 & $1987-1996$ & 0.29 & 0.87 & 0.59 \\
\hline $1980-1987$ & 0.26 & 0.86 & 0.51 & $1988-1996$ & 0.29 & 0.84 & 0.53 \\
\hline
\end{tabular}

